\title{
Effectiveness of Resistance Circuit-Based Training for Maximum Oxygen Uptake and Upper-Body One-Repetition Maximum Improvements: A Systematic Review and Meta-Analysis
}

\author{
Francisco Antonio Muñoz-Martínez ${ }^{1}$ Jacobo Á. Rubio-Arias ${ }^{1,2}$. \\ Domingo Jesús Ramos-Campo ${ }^{1,2} \cdot$ Pedro E. Alcaraz ${ }^{1,2}$
}

(C) Springer International Publishing AG 2017

\begin{abstract}
Background It is well known that concurrent increases in both maximal strength and aerobic capacity are associated with improvements in sports performance as well as overall health. One of the most popular training methods used for achieving these objectives is resistance circuit-based training.

Objective The objective of the present systematic review with a meta-analysis was to evaluate published studies that have investigated the effects of resistance circuit-based training on maximum oxygen uptake and one-repetition maximum of the upper-body strength (bench press exercise) in healthy adults.

Methods The following electronic databases were searched from January to June 2016: PubMed, Web of Science and Cochrane. Studies were included if they met the following criteria: (1) examined healthy adults aged between 18 and 65 years; (2) met the characteristics of resistance circuitbased training; and (3) analysed the outcome variables of maximum oxygen uptake using a gas analyser and/or onerepetition maximum bench press.

Results Of the 100 articles found from the database search and after all duplicates were removed, eight articles were analysed for maximum oxygen uptake. Of 118 healthy adults who performed resistance circuit-based training,
\end{abstract}

Jacobo Á. Rubio-Arias

jararias@ucam.edu

1 UCAM Research Center for High Performance Sport, Catholic University San Antonio, Campus de los Jerónimos, No. 135 Guadalupe, 30107 Murcia, Spain

2 Department of Physical Activity and Sports Sciences, Faculty of Sports, UCAM, Catholic University San Antonio, Murcia, Spain maximum oxygen uptake was evaluated before and after the training programme. Additionally, from the 308 articles found for one-repetition maximum, eight articles were analysed. The bench press one-repetition maximum load, of 237 healthy adults who performed resistance circuitbased training, was evaluated before and after the training programme. Significant increases in maximum oxygen uptake and one-repetition maximum bench press were observed following resistance circuit-based training. Additionally, significant differences in maximum oxygen uptake and one-repetition maximum bench press were found between the resistance circuit-based training and control groups.

Conclusions The meta-analysis showed that resistance circuit-based training, independent of the protocol used in the studies, is effective in increasing maximum oxygen uptake and one-repetition maximum bench press in healthy adults. However, its effect appears to be larger depending on the population and training characteristics. For large effects in maximum oxygen uptake, the programme should include $\sim 14-30$ sessions for $\sim 6-12$ weeks, with each session lasting at least $\sim 20-30 \mathrm{~min}$, at intensities between $\sim 60$ and $90 \%$ one-repetition maximum. For large effects in one-repetition maximum bench press, the data indicate that intensity should be $\sim 30-60 \%$ one-repetition maximum, with sessions lasting at least $\sim 22.5-60 \mathrm{~min}$. However, the lower participant's baseline fitness level may explain the lighter optimal loads used in the circuit training studies where greater strength gains were reported. 


\section{Key Points}

Resistance circuit-based training is an effective training method for the concurrent development of maximum oxygen consumption $\left(\mathrm{VO}_{2 \max }\right)$ and onerepetition maximum (1-RM) bench press in healthy adults, independent of participant and load characteristics of the included studies. However, a proper manipulation of the variables that determine the training load could intensify $\mathrm{VO}_{2 \max }$ or 1-RM adaptations.

Regarding $\mathrm{VO}_{2 \max }$, the effect of this training protocol is significantly greater (large or very large effect size $)$ at an intensity $>60 \% \quad 1-\mathrm{RM}(\sim 60-90 \%$ 1 -RM), for $\leq 12$ weeks ( $\sim 6-12$ weeks), with $<30$ sessions ( $\sim 14-30$ sessions), and with sessions lasting $<30 \mathrm{~min}(\sim 20-30 \mathrm{~min})$.

For 1-RM bench press improvements, the effect of resistance circuit-based training was significantly larger in non-overweight subjects (body mass index $\left.\leq 25 \mathrm{~kg} / \mathrm{m}^{2}\right)$, sedentary individuals, at an intensity $<60 \% \quad 1-\mathrm{RM}(\sim 30-60 \%$ 1-RM $)$, and with work sessions lasting $<60 \mathrm{~min}(\sim 22.5-60 \mathrm{~min})$. However, while this finding suggests that lower loads produce greater gains in lesser trained individuals, the optimal intensity for trained individuals is likely higher.

\section{Introduction}

Improvements in sports performance in most team sports are determined by a high demand of aerobic/anaerobic metabolism [1-3], maximal strength [4, 5], mechanical power [6,7], speed and agility [8,9]. Thus, success or failure in these sports is largely dependent on the optimal training plan used for developing these abilities, which are often trained simultaneously (i.e. concurrent training). Furthermore, different physical activity guidelines published by internationally renowned associations [10-13], and from different review articles, have shown that increases in maximal strength, along with cardiovascular fitness, provide overall health benefits for the general public [14], the elderly [15, 16], as well as for the treatment and quality-of-life improvements in people with different pathologies [17-20].

One of the common measures of cardiovascular performance is maximum oxygen uptake $\left(\mathrm{VO}_{2 \max }\right)$, which is defined as the largest volume of oxygen that an organism can capture, use and transport during intense exercise [21]. Maximum oxygen uptake is generally used as the 'gold standard' when evaluating aerobic performance and is considered to be a physiological determinant of an individual's functional capacity, which has a fundamental role in endurance sports [22]. Likewise, the one-repetition maximum (1-RM) is the best variable used to evaluate maximal dynamic strength. The 1-RM is defined as the greatest load that one can mobilise during the concentric phase of a movement in a single contraction [23], and indicates the maximal voluntary force of the muscle or muscle group being exerted.

Since the 1970s, there has been a search for a single type of concurrent training that improves both maximal strength and aerobic endurance while using a reduced session duration for its application in competitive sports, as well as in the area of health [24]. To date, the most traditionally used concurrent training method is resistance circuit-based training (RCT). In its early employment, RCT comprised single sets of several different exercises completed in succession, with little rest between exercises. The exercises were generally performed at low intensity $(40-60 \%$ of 1-RM), with a high number of repetitions (12-15), and more often, using a set length of time (e.g. $30 \mathrm{~s}$ ) with a very short rest period between exercises (1:1). The purported benefit of this form of training was that it produced improvements in strength, muscular endurance and aerobic conditioning in one workout $[25,26]$. Presently, and together with the new training trends (e.g. CrossFit ${ }^{\mathrm{TM}}$ and others), there have been some slight modifications of the earliest method of RCT, such as using high loads ( $>60 \%$ 1-RM) and a corresponding lower number of repetitions $(<12)$, to additionally promote neuromuscular adaptations $[27,28]$.

One of the acute responses of RCT is that the heart rate is typically higher than during most other resistance training programmes because of the short rest periods between exercises [29, 30]. In addition, RCT has been shown to elicit a high oxygen uptake (45\% of subjects' $\mathrm{VO}_{2 \max }$ ) [26], greater excess post-exercise oxygen consumption during the first $30 \mathrm{~min}$ of recovery compared with a treadmill exercise that matches aerobic energy expenditure [31] and relatively higher lactate levels (16fold higher after RCT vs. walking at the same $\mathrm{VO}_{2}$ ) [30]. From a long-term point of view, Gettman et al. [32] concluded that programmes of running combined with circuit weight training or circuit weight training alone were very effective and equal in the improvements observed for $\mathrm{VO}_{2 \max }$ and maximum oxygen pulse, strength and body composition. Similarly, Petersen et al. [33] have shown that $\mathrm{VO}_{2 \max }$, maximal stroke volume and cardiac output of previously trained subjects were 
increased by $8 \%$ with RCT. Furthermore, Alcaraz et al. [27] showed that RCT increases maximal strength in resistance-trained men comparable to that produced using traditional resistance training. However, other authors do not show significant improvements in $\mathrm{VO}_{2 \max }$ [30, 34, 35], and maximal strength [36] using RCT in healthy adults.

One possible explanation for these contradictory findings could be that, during concurrent training, the muscle is repeatedly subjected to divergent contractile stimuli. Therefore, this "interference effect" [37, 38] alters the specificity of the adaptive response to such an extent that gains in hypertrophy, strength and power are typically attenuated when compared with traditional resistance training [39] alone. However, although it is likely that RCT can improve cardiovascular conditioning and maximal strength, some studies recommend this type of training in people with lower basal levels of fitness, concluding that the aerobic effects are much less pronounced in those who are more fit [36]. For example, Kraemer et al. [40] concluded that in aerobically fit individuals, using an intense resistance programme (which also included two RCT sessions/week for 3 months) did not improve $\mathrm{VO}_{2 \max }$. Similarly, some studies have shown that improvements in maximal strength following RCT are more potent in previously untrained people [41]. Therefore, it is hypothesised that RCT may be a good introductory form of training for developing both $\mathrm{VO}_{2 \text { máx }}$ and 1-RM, but the adaptations in trained participants could be low or non-existent.

The controversial findings in the literature regarding RCT may also be the result of the numerous variables that must be manipulated in the training protocol (e.g. number of repetitions, sets, recovery and load intensity). Therefore, establishing an adequate dose of training and the specific effects that it produces is not possible. Consequently, it is difficult to clearly determine the efficacy of this type of concurrent training on $\mathrm{VO}_{2 \max }$ and the upper body 1-RM of healthy adults. Although this modality of training has been, and is still being used by trained individuals and for improving overall health, to our knowledge, no reviews (narrative, systematic or metaanalysis) have tried to elucidate the adequate dose of a RCT protocol for improving $\mathrm{VO}_{2 \max }$ and the upper body 1-RM of healthy adults. Only Gettman and Pollock [26] critically reviewed past knowledge on RCT and compared results of studies using various types of strength development equipment and protocols of training. Thus, the first objective of the present systematic review with a meta-analysis was to assess the effect of RCT on $\mathrm{VO}_{2 \max }$ and upper body 1-RM bench press. A second aim was to determine which training characteristics produced the greatest adaptations of the variables studied.

\section{Methods}

\subsection{Study Design}

The methodological process was based on the recommendations indicated by the Preferred Reporting Items for Systematic Reviews and Meta-Analyses declaration [42]. The eligibility criteria were established by the authors. For the meta-analysis, only experimental/quasi-experimental research that studied resistance circuit-based training (circuit training, circuit weight training, circuit strength training and circuit resistance training) was considered. No restrictions for the search date were applied. However, articles that were not in the English language and previously published reviews or meta-analyses were excluded. Two different authors (J.A.R.A. and F.A.M.M.) performed the search independently, and the results of the search for the two authors were identical.

\subsection{Search Profile}

Between January and June of 2016, a database search for scientific articles related to resistance circuit-based training and its effects on $\mathrm{VO}_{2 \max }$ and 1-RM bench press was performed. The databases for gathering the articles were PubMed, Web of Science and Cochrane.

The following combination of descriptors was used: 'circuit training' OR 'circuit weight training' OR 'circuit strength training' OR 'circuit resistance training'. The Boolean operator 'AND' was used to combine these descriptors with: ' $\mathrm{VO}_{2}$ ' $\mathrm{OR}$ 'oxygen consumption' $\mathrm{OR}$ 'oxygen' OR 'strength' OR 'resistance'. The flow diagrams for the entire search process for both variables are shown in Fig. 1.

\subsection{Selection Criteria}

Research studies were excluded if they: (1) evaluated a sample population with pathologies or one that was not between 18 and 65 years of age; (2) were published in a language other than English; (3) were reviews or articles providing recommendations or position statements on how to conduct RCT; (4) did not evaluate regimens characteristic of RCT (i.e. successive sets of different exercises, little rest time, appropriate equipment); (5) did not specify the test used, such as $\mathrm{VO}_{2 \max }$ or maximal strength; (6) examined a combination of different training protocols simultaneously, including RCT; (7) did not provide or specify numerical data; and (8) examined the acute effects of RCT.

Specific inclusion criteria for $\mathrm{VO}_{2 \max }$ were as follows: (1) $\mathrm{VO}_{2 \max }$ had to be assessed through a sub-maximum or 
a

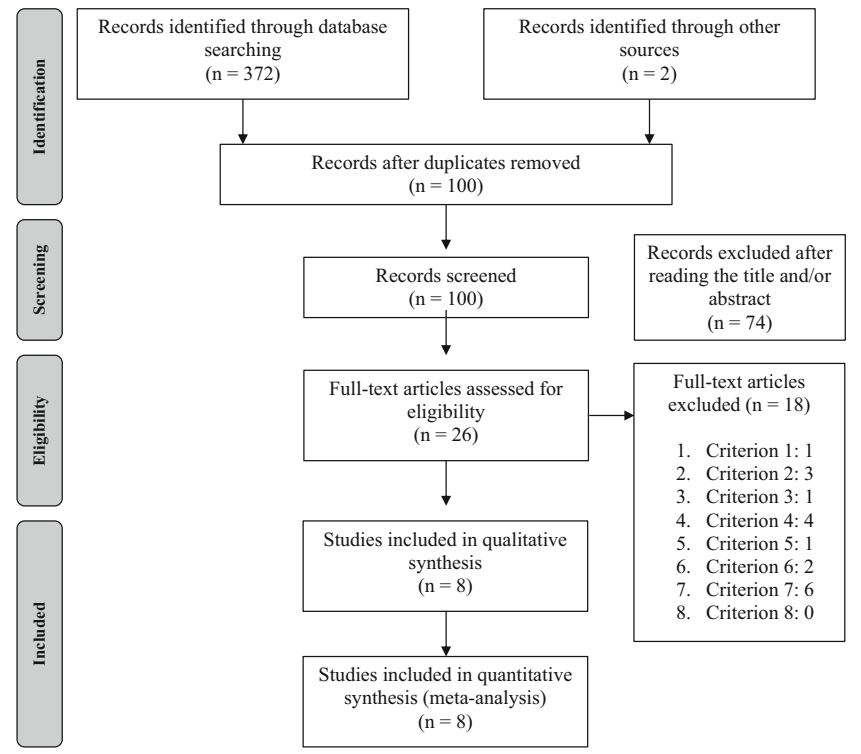

Fig. 1 Search process flow diagrams for: (a) maximum oxygen uptake $\left(\mathrm{VO}_{2 \max }\right)$ and (b) one-repetition maximum (1-RM) bench press. Criteria: (1) evaluated a sample population with pathologies or one that was not between 18 and 65 years of age, (2) were published in a language other than English, (3) were reviews or articles providing recommendations or position statements on how to conduct resistance circuit-based training (RCT), (4) did not evaluate regimens

maximum test with gas exchange in an ergometer; and (2) the values from the test had to be expressed as $\mathrm{mL} / \mathrm{kg} / \mathrm{min}$. The specific inclusion criteria for upper body maximal strength were: (1) the use of the 1-RM test; and (2) performed with a bench press.

\subsection{Evaluation of the Methodology of the Studies Selected}

The methodological quality of the selected studies was assessed based on the modified PEDro scale [43] comprising the following parameters: (1) the eligibility criteria were specified; (2) the participants were randomly assigned to the groups (in a crossover study, the participants were randomly assigned to treatment groups); (3) the assignment was hidden; (4) the groups were similar at the start of the study in relation to the most important prognostic indicators; (5) all the participants were blinded; (6) there was blinding of all the therapists that administered the therapy; (7) there was blinding of the evaluators that measured at least one key result; (8) measurements of key results were obtained from more than $85 \%$ of the participants that were initially assigned to the groups; (9) all the participants whose results were available received treatment or were part of the control group according to which they were assigned, or when this was not the case, the data for at least one key result were analysed by 'intention-to-treat'; (10) b

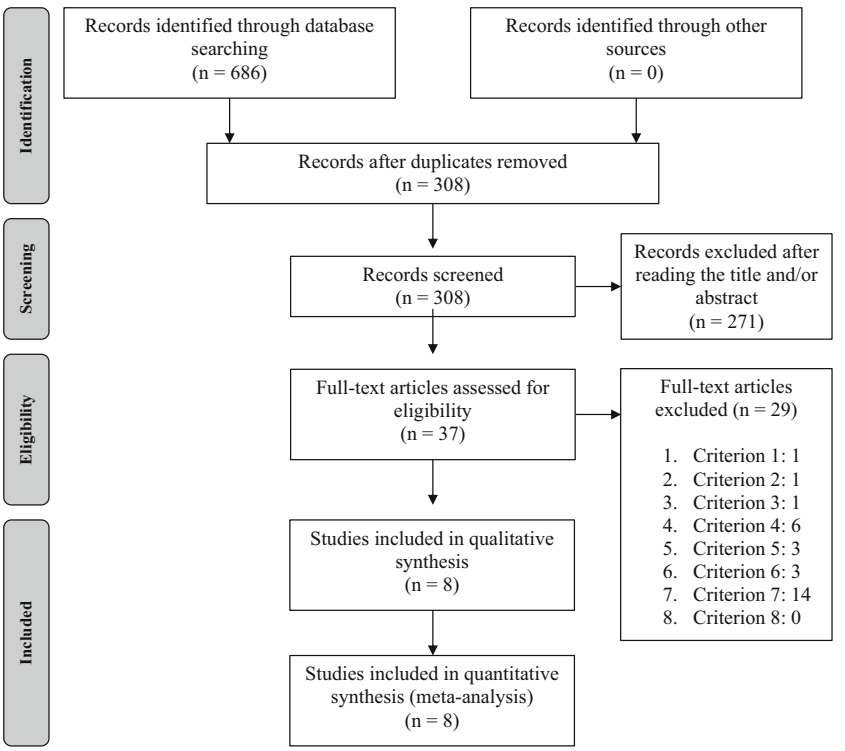

characteristic of RCT (i.e. successive sets of different exercises, little rest time, appropriate equipment), (5) did not specify the test used, such as $\mathrm{VO}_{2 \max }$ or maximal strength, (6) examined a combination of different training protocols simultaneously, including RCT, (7) did not provide or specify numerical data, and (8) examined the acute effects of RCT

the results of the statistical comparisons between groups were reported for at least one key result; and (11) the study provided both specific and variability measurements for at least one key result.

\subsection{Statistical Analysis}

The meta-analysis and the statistical analysis were conducted using the Review Manager software (RevMan 5.2; Cochrane Collaboration, Oxford, UK). In each study, the effect size (ES) of the intervention was calculated as the difference between before and after the intervention for $\mathrm{VO}_{2 \max }(\mathrm{mL} / \mathrm{kg} / \mathrm{min})$ and 1-RM $(\mathrm{kg})$. The ES of RCT was also calculated as the difference before and after the intervention between the participants who performed RCT and the control group.

Each difference of the means was weighed according to the inverse variance method [44]. The characteristics of the population and the training programmes from each of the studies were taken into account (Tables 1, 2, 3 and 4). The differences between the means were standardised by dividing them by their corresponding standard deviations. The standardised mean differences (SMD), and their confidence intervals (CI), from each assay were grouped through the use of a fixed-effects model [45].

The heterogeneity between the studies was evaluated through $I^{2}$ statistics. A scale of magnitude was 
Table 1 Main characteristics of included studies in the maximum oxygen uptake meta-analysis

\begin{tabular}{|c|c|c|c|c|c|c|c|c|}
\hline Study, year & $\mathrm{TC}$ & $\mathrm{C}(n)$ & $\mathrm{CT}(n)$ & $\mathrm{M}(\%)$ & $\mathrm{F}(\%)$ & Age (years) & BMI $\left(\mathrm{kg} / \mathrm{m}^{2}\right)$ & Fitness level \\
\hline Chtara et al. [50] & $\mathrm{RCT}$ & 9 & 9 & 100 & - & $21.4 \pm 1.3$ & 22.7 & Active \\
\hline Gettman et al. [51] & $\mathrm{RCT}$ & 14 & 11 & 100 & - & 29 & 26.4 & Trained \\
\hline \multirow[t]{2}{*}{ Gettman et al. [32] } & RCT_M & 14 & 14 & 53.2 & 46.8 & 35.9 & 26.8 & Active \\
\hline & RCT_F & 12 & 12 & & & & 24.5 & \\
\hline \multirow[t]{2}{*}{ Haennel et al. [52] } & HCT_H & 8 & 8 & 100 & - & $42.2 \pm 2.1$ & 26.1 & Active \\
\hline & HCT_L & & 8 & & & & & \\
\hline Kaikkonen et al. [53] & $\mathrm{RCT}$ & 27 & 27 & - & - & $42.5 \pm 7$ & $26.9 \pm 3.2$ & Sedentary \\
\hline Messier and Dill [54] & $\mathrm{RCT}$ & - & 12 & 100 & - & - & - & Active \\
\hline Murray et al. [55] & RCT & - & 9 & 100 & - & $28 \pm 1.2$ & - & Active \\
\hline Petersen et al. 1989 [33] & HVC & 8 & 8 & 100 & - & $21.6 \pm 0.7$ & 24.3 & Trained \\
\hline
\end{tabular}

Data are mean, mean \pm standard deviation

$B M I$ body mass index, $C$ control group, $C T$ circuit-based training, $F$ female, $H$ high, $H C T$ hydraulic circuit training, $H V C$ high-velocity circuit training, $L$ low, $M$ male, $R C T$ resistance circuit-based training, $T C$ type of circuit

Table 2 Main characteristics of included studies in the one repetition-maximum bench press meta-analysis

\begin{tabular}{|c|c|c|c|c|c|c|c|c|}
\hline Study, year & $\mathrm{TC}$ & $\mathrm{C}(n)$ & $\mathrm{CT}(n)$ & $\mathrm{M}(\%)$ & $\mathrm{F}(\%)$ & Age (years) & BMI $\left(\mathrm{kg} / \mathrm{m}^{2}\right)$ & Fitness level \\
\hline Alcaraz et al. [27] & HRC & 7 & 15 & 100 & - & $22.7 \pm 3.3$ & 24.3 & Trained \\
\hline Camargo et al. [56] & RCT & 7 & 7 & 100 & - & $29 \pm 3.0$ & $27.3 \pm 2.0$ & Sedentary \\
\hline \multirow[t]{2}{*}{ Dorgo et al. [57] } & MRT & - & 53 & 54.8 & 45.2 & $25.6 \pm 6.0$ & 25.5 & Active \\
\hline & RCT & & 31 & & & $25.5 \pm 5.2$ & 26.1 & \\
\hline \multirow[t]{2}{*}{ Esquivel and Welsch [58] } & RCT_1 & - & 15 & 100 & - & $22 \pm 1.8$ & $27.9 \pm 7.0$ & Active \\
\hline & RCT_2 & & 20 & & & $21 \pm 1.8$ & $26.2 \pm 4.4$ & \\
\hline \multirow[t]{2}{*}{ Gettman et al. [32] } & RCT_M & 14 & 14 & 53.2 & 46.8 & 35.9 & 26.8 & Active \\
\hline & RCT_F & 12 & 12 & - & 50 & & 24.5 & \\
\hline \multirow[t]{2}{*}{ Mate-Muñoz et al. [59] } & RCT & 12 & 10 & 100 & - & $21.8 \pm 1.1$ & 22.6 & Active \\
\hline & UCT & & 12 & & & $21.5 \pm 3.0$ & 24 & \\
\hline Rahmani-Nia et al. [60] & RCT & 20 & 20 & 100 & - & $22.5 \pm 1.1$ & 22.7 & Active \\
\hline \multirow[t]{2}{*}{ Wilmore et al. [36] } & RCT_M & 10 & 16 & 57.1 & 42.9 & - & 23.6 & Sedentary \\
\hline & RCT_F & 11 & 12 & & & & & \\
\hline
\end{tabular}

Data are mean, mean \pm standard deviation

$B M I$ body mass index, $C$ control group, $C T$ circuit-based training, $F$ female, $H R C$ high-intensity resistance circuit training, $M$ male, $M R T$ manual resistance training, $R C T$ resistance circuit-based training, $T C$ type of circuit, $U C T$ unstable circuit training

implemented for the interpretation of heterogeneity of the results, where $<25 \%$ was assessed as a low magnitude, $50 \%$ was medium magnitude and $>75 \%$ was high magnitude [46]. The analysis between the subgroups in relation to the population characteristics and the training performed was conducted through dichotomous or continuous variables that could have an influence on the improved results after RCT. In most cases, the median was used as the cutoff value of the variables studied, allowing for pair-wise comparison. However, in specific cases, the cut-off was established in an arbitrary way. The changes in those factors that could potentially be influential were expressed and analysed as values prior to the intervention minus the values found after the intervention. Publication bias was evaluated through an asymmetry test as estimated from a funnel plot. A $p$ value of less than 0.05 was considered to be statistically significant. The ES was calculated using Cohen's guidelines: $\mathrm{ES}=\frac{M_{\text {pre }}-M_{\text {post }}}{S D_{\text {pre }}}\left(1-\frac{3}{4 n-5}\right)$ for related samples and $\mathrm{ES}=\frac{\left(M_{g 1}-M_{g 2}\right)}{\mathrm{SD}_{\text {pool }}}$ for independent samples, where $M$ is the mean, $M_{\text {pre }}$ is the mean before the exercise programme, $M_{\text {post }}$ is the mean after the exercise programme, $M_{g 1}$ is the mean of the first group after the exercise programme, $M_{g 2}$ is the mean of second group after the exercise programme, and $S D_{\text {pool }}=$ , where $\mathrm{SD}$ is the standard deviation and $n$ is the sample size. Threshold values for ES were $>0.2$ (small), $>0.6$ (moderate), $>1.2$ (large) and $>2.0$ (very large) [47]. 
Table 3 Characteristics of the resistance circuit-based training (RCT) protocols of studies included in the maximum oxygen uptake $\left(\mathrm{VO}_{2 \mathrm{max}}\right)$ meta-analysis

\begin{tabular}{|c|c|c|c|c|c|c|c|c|c|c|}
\hline Study, year & $\mathrm{TC}$ & $\begin{array}{l}\text { Intensity } \\
(\% 1- \\
\mathrm{RM})\end{array}$ & $\begin{array}{l}\text { Frequency } \\
\left(\text { week }^{-1}\right)\end{array}$ & $\begin{array}{l}\text { Session } \\
\text { length } \\
(\mathrm{min})\end{array}$ & $\begin{array}{l}\text { Duration } \\
\text { (weeks) }\end{array}$ & $\begin{array}{l}\text { No. of } \\
\text { sessions }\end{array}$ & $\begin{array}{l}\text { No. of } \\
\text { exercises }\end{array}$ & $\begin{array}{l}\text { No. of repetitions } \\
\text { or time (s) per } \\
\text { exercise }\end{array}$ & $\begin{array}{l}\text { No. of } \\
\text { rounds }\end{array}$ & $\begin{array}{l}\Delta \mathrm{VO}_{2 \max } \\
(\%)\end{array}$ \\
\hline Chtara et al. [50] & $\mathrm{RCT}$ & Low & 2 & 30 & 12 & 24 & 6 & $30-40$ & 4 & 5.8 \\
\hline Gettman et al. [51] & $\mathrm{RCT}$ & 50 & 3 & $23-30$ & 20 & 60 & 10 & 15 & 2 & 3.5 \\
\hline Gettman et al. [32] & $\begin{array}{l}\text { RCT_M } \\
\text { RCT_F }\end{array}$ & $30-40$ & 3 & - & 12 & 36 & 10 & $12-15$ & 3 & $\begin{array}{l}11.9 \\
13.4\end{array}$ \\
\hline Haennel et al. [52] & $\begin{array}{l}\text { HCT_H } \\
\text { HCT_L }\end{array}$ & $\begin{array}{l}\sim 60 \\
\sim 50\end{array}$ & 3 & 27 & 9 & 27 & 9 & - & - & $\begin{array}{l}10.1 \\
11.1\end{array}$ \\
\hline $\begin{array}{l}\text { Kaikkonen et al. } \\
\text { [53] }\end{array}$ & $\mathrm{RCT}$ & 20 & 3 & 30 & 12 & 36 & 10 & 40 & 3 & 10.4 \\
\hline $\begin{array}{l}\text { Messier and Dill } \\
\text { [54] }\end{array}$ & $\mathrm{RCT}$ & $\begin{array}{c}67-80 / \\
<65\end{array}$ & 3 & 20.3 & 10 & 30 & 12 & $\begin{array}{l}8-12 \\
15-20\end{array}$ & - & 13.6 \\
\hline Murray et al. [55] & RCT & $80-93$ & 2 & 35 & 7 & 14 & 12 & - & - & 3.8 \\
\hline Petersen et al. [33] & НCT & - & 3.5 & - & 6 & 21 & 10 & 20 & $2-3$ & 7.8 \\
\hline
\end{tabular}

Data are mean, range or $n$

$F$ female, $H C T$ hydraulic circuit training, $M$ male, $T C$ type of circuit, 1-RM one repetition-maximum

Table 4 Characteristics of the resistance circuit-based training (RCT) protocols of studies included in the one repetition-maximum (1-RM) bench press meta-analysis

\begin{tabular}{|c|c|c|c|c|c|c|c|c|c|c|}
\hline Study, year & $\mathrm{TC}$ & $\begin{array}{l}\text { Intensity } \\
(\% 1-\mathrm{RM})\end{array}$ & $\begin{array}{l}\text { Frequency } \\
\left(\text { week }^{-1}\right)\end{array}$ & $\begin{array}{l}\text { Session } \\
\text { length } \\
(\mathrm{min})\end{array}$ & $\begin{array}{l}\text { Duration } \\
\text { (weeks) }\end{array}$ & $\begin{array}{l}\text { No. of } \\
\text { sessions }\end{array}$ & $\begin{array}{l}\text { No. of } \\
\text { exercises }\end{array}$ & $\begin{array}{l}\text { No. of repetitions or } \\
\text { time (s) per exercise }\end{array}$ & $\begin{array}{l}\text { No. } \\
\text { of } \\
\text { sets }\end{array}$ & $\begin{array}{l}\Delta \\
1-\mathrm{RM} \\
(\%)\end{array}$ \\
\hline $\begin{array}{l}\text { Alcaraz et al. } \\
\text { [27] }\end{array}$ & HRC & $85-90$ & 3 & $55-78$ & 8 & 24 & 6 & 6 & $3-6$ & 21 \\
\hline $\begin{array}{l}\text { Camargo et al. } \\
\text { [56] }\end{array}$ & RCT & 60 & 3 & 35 & 12 & 36 & - & 15 & 3 & 13.2 \\
\hline $\begin{array}{l}\text { Dorgo et al. } \\
\text { [57] }\end{array}$ & $\begin{array}{l}\text { MRT } \\
\text { RCT }\end{array}$ & $67-80$ & 3 & 60 & 14 & 42 & $6-9$ & $8-12$ & $2-4$ & $\begin{array}{l}7.3 \\
9.8\end{array}$ \\
\hline $\begin{array}{l}\text { Esquivel and } \\
\text { Wellsch [58] }\end{array}$ & $\mathrm{RCT}$ & $60-80$ & 3 & 60 & 5 & 15 & 17 & $8-12$ & $\begin{array}{l}1 \\
3\end{array}$ & 22.4 \\
\hline $\begin{array}{l}\text { Gettman et al. } \\
\text { [32] }\end{array}$ & $\begin{array}{l}\text { RCT_M } \\
\text { RCT_F }\end{array}$ & $30-40$ & 3 & - & 12 & 36 & 10 & $12-15$ & 3 & $\begin{array}{l}13.6 \\
20\end{array}$ \\
\hline $\begin{array}{l}\text { Mate-Muñoz } \\
\text { et al. [59] }\end{array}$ & $\begin{array}{l}\text { RCT } \\
\text { UCT }\end{array}$ & $\begin{array}{l}\text { High (10 } \\
\text { RPE) }\end{array}$ & 3 & $45-65$ & 7 & 21 & 8 & 15 & 3 & $\begin{array}{l}4.4 \\
4.7\end{array}$ \\
\hline $\begin{array}{l}\text { Rahmani-Nia } \\
\text { et al. [60] }\end{array}$ & RCT & $45-60$ & 3 & - & 8 & 24 & 6 & $12-15$ & 3 & 14 \\
\hline $\begin{array}{l}\text { Wilmore et al. } \\
\text { [36] }\end{array}$ & $\begin{array}{l}\text { RCT_M } \\
\text { RCT_F }\end{array}$ & $40-55$ & 3 & 22.5 & 10 & 30 & 10 & 30 & 3 & $\begin{array}{l}83 \\
20.2\end{array}$ \\
\hline
\end{tabular}

Data are mean, range or $n$

$F$ female, $H R C$ high-intensity resistance circuit training, $M$ male, $M R T$ manual resistance training, $R P E$ rate of perceived exertion, $T C$ type of circuit, $U C T$ unstable circuit training, $\Delta$ indicates change

\section{Results}

The initial search, which was based on the effect of resistance circuit-based training on $\mathrm{VO}_{2 \max }$, identified 372 articles from the databases and two articles from other sources (reference lists of articles identified by the search).
After excluding duplicate articles, eight articles that met the criteria were left, and these were selected for the metaanalysis (Fig. 1a). A second search, which focused on the effect of resistance circuit-based training on maximal strength, identified 686 articles from the databases. After removing the duplicates, eight articles met the inclusion 
criteria and were used for the meta-analysis (Fig. 1b). The quality (internal validity) of the articles was analysed through the use of the PEDro scale [43, 48, 49], and the overall average score was moderate $\left(4.9\right.$ for $\mathrm{VO}_{2 \max }$, and 6.6 for $1-\mathrm{RM}$ out of 11 possible points).

\subsection{Maximum Oxygen Uptake}

The effect of RCT on $\mathrm{VO}_{2 \max }$ was measured in 118 participants. No bias was presented in the set of publications that were included in the study. The results of the overall effects on $\mathrm{VO}_{2 \max }$ before and after the RCT programme showed significant improvement between pre- and post-test variables (ES: $1.53 ; p<0.0001 ; \mathrm{SMD}=1.10,95 \% \mathrm{CI}$ $0.81-1.39$ ), with an average heterogeneity of $I^{2}=72 \%$ (Fig. 2a) [32, 33, 50-55]. Additionally, there were significant improvements in participants belonging to the RCT group compared with the control group (ES: 1.48; $p<0.0001 ; \mathrm{SMD}=0.83,95 \%$ CI $0.52-1.14$ ), with an average heterogeneity of $I^{2}=65 \% \quad$ (Fig. 2b) $[32,33,50-53]$.

Table 1 shows the participant characteristics of the articles included in the meta-analysis for $\mathrm{VO}_{2 \max }$ [32, 33, 50-55], the characteristics of the RCT used and the specific test used for measuring $\mathrm{VO}_{2 \max }$ in each study.
There were significant differences in potential moderating factors regarding $\mathrm{VO}_{2 \max }(p<0.05)$ in all subgroups (Table 5; Fig. 2a, b).

When comparing the characteristics of each subgroup (Table 5), significant differences were not found when the participants were divided as a function of their age, body mass index (BMI), sex and fitness level. When the exercise characteristics were analysed, the results showed that there were significant differences among participants as a function of the total duration (weeks) of the training programmes. There were greater changes in participants who performed the training programme for $\leq 12$ weeks as compared with those who trained for $>12$ weeks (ES: $\leq 12$ weeks: 2.34 [33, 52, 54, 55]; >12 weeks: 0.71 $[32,50,51,53] ; p=0.005)$. Additionally, there were statistically significant differences found in the number of total training sessions $(\mathrm{ES}:<30 \quad$ sessions $=1.75$ $\left[\begin{array}{lll}51, & 52, & 54\end{array}\right] ; \geq 30 \quad$ sessions $=1.30 \quad[32, \quad 53, \quad 54]$; $p<0.0001)$. Along the same lines, the total duration of the sessions was also an influencing factor. Sessions lasting for $<30 \mathrm{~min}$ (ES: 1.85) [51, 52, 54] were associated with significantly greater improvements in $\mathrm{VO}_{2 \max }(p=0.03)$ compared with sessions lasting for $\geq 30 \mathrm{~min}$ (ES: 0.71) $[50,53,55]$. Last, statistically significant differences were also observed among participants who performed RCT at

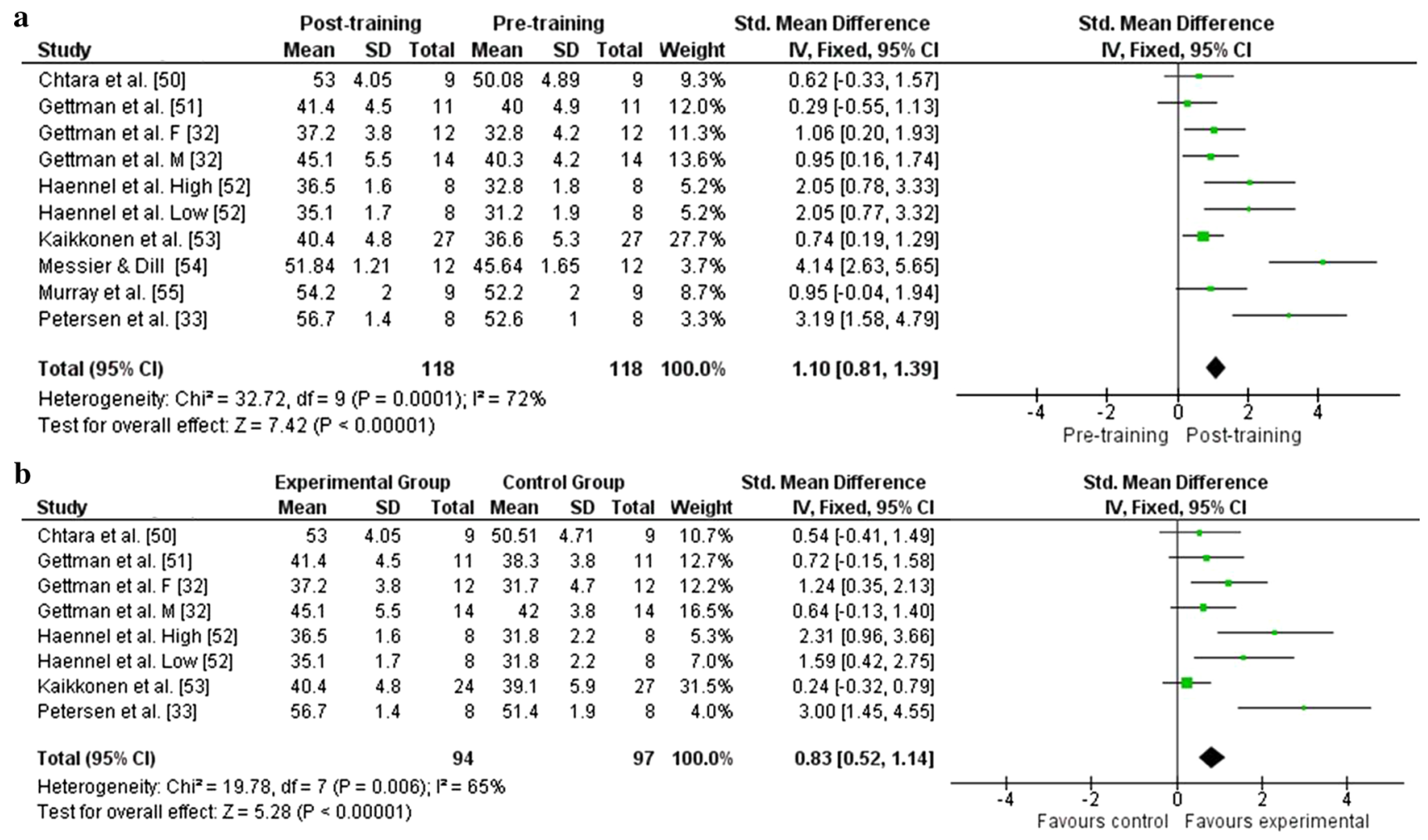

Fig. 2 Total effects of resistance circuit-based training $(\mathrm{RCT})$ on maximum oxygen uptake $\left(\mathrm{VO}_{2 \mathrm{max}}\right)[\mathrm{mL} / \mathrm{kg} / \mathrm{min}]$ : a pre- vs. post-training; and b control group vs. RCT. $C I$ confidence interval, $F$ female, $H$ high; $I V$ inverse variance, $L$ low, $M$ male, $S D$ standard deviation, $S t d$ standardised 
Table 5 Subgroup analyses assessing potential moderating factors of maximum oxygen uptake $\left(\mathrm{VO}_{2 \max }\right)$ in studies included in the metaanalysis

\begin{tabular}{|c|c|c|c|c|c|c|c|}
\hline \multirow[t]{2}{*}{ Group } & \multirow{2}{*}{$\begin{array}{l}\text { Circuit training } \\
\text { groups }(n)\end{array}$} & \multirow[t]{2}{*}{ Studies } & \multicolumn{5}{|c|}{$\mathrm{VO}_{2 \max }$} \\
\hline & & & ES & $\operatorname{SMD}(95 \% \mathrm{CI})$ & $I^{2}$ & $p$ Value & $P_{\text {Difference }}$ \\
\hline \multicolumn{8}{|c|}{ Population characteristics } \\
\hline \multicolumn{8}{|c|}{ Age, years [range 21.1-42.5] } \\
\hline$>35.7$ & 5 & M [32]; F [32]; H [52]; L [52]; [53] & 1.78 & $-1.22[-1.64,-0.81]$ & 67 & $<0.0001$ & \multirow[t]{2}{*}{0.1} \\
\hline$\leq 35.7$ & 4 & {$[33,50,51,55]$} & 0.71 & $-0.72[-1.15,-0.30]$ & 0 & $<0.0009$ & \\
\hline \multicolumn{8}{|c|}{ BMI, $\mathrm{kg} / \mathrm{m}^{2}$ [range $22.7-26.9$ ] } \\
\hline$>25$ & 5 & M [32]; [51]; H [52]; L [52]; [53] & 1.37 & $-0.91[-1.28,-0.55]$ & 54 & $<0.0001$ & \multirow[t]{2}{*}{0.45} \\
\hline$\leq 25$ & 3 & $\mathrm{~F}[32] ;[33,50]$ & 1.74 & $-1.18[-1.76,-0.60]$ & 73 & $<0.0001$ & \\
\hline \multicolumn{8}{|l|}{ Sex } \\
\hline M & 8 & M [32]; [33, 50, 51]; H [52]; L [52]; [54, 55] & 1.7 & $-1.27[-1.64,-0.90]$ & 77 & $<0.0001$ & \multirow[t]{3}{*}{0.29} \\
\hline $\mathrm{F}$ & 1 & $\mathrm{~F}[32]$ & 0.97 & $-1.06[-1.93,-0.20]$ & - & 0.02 & \\
\hline Mixed & 1 & {$[53]$} & 0.7 & $-0.74[-1.29,-0.19]$ & - & 0.009 & \\
\hline \multicolumn{8}{|l|}{ Fitness level } \\
\hline Sedentary & 1 & {$[53]$} & 0.7 & $-0.74[-1.31,-0.17]$ & - & 0.01 & \multirow[t]{3}{*}{0.21} \\
\hline Active & 7 & M [32]; F [32]; [50]; H [52]; L [52]; [54, 55] & 1.52 & $-1.33[-1.71,-0.94]$ & 70 & $<0.0001$ & \\
\hline Trained & 2 & {$[33,51]$} & 1.95 & $-0.91[-1.66,-0.17]$ & - & 0.02 & \\
\hline \multicolumn{8}{|c|}{ Exercise characteristics } \\
\hline \multicolumn{8}{|c|}{ Number of sessions [range 14-60] } \\
\hline$\geq 30$ & 5 & M [32]; F [32]; [51, 53, 54] & 1.3 & $-0.94[-1.29,-0.59]$ & 80 & $<0.0001$ & \multirow[t]{2}{*}{$<0.0001$} \\
\hline$<30$ & 5 & {$[33,50] ; \mathrm{H}[52] ; \mathrm{L}[52] ;[55]$} & 1.75 & $-1.45[-1.96,-0.81]$ & 60 & $<0.0001$ & \\
\hline \multicolumn{8}{|c|}{ Duration, weeks [range 6-20] } \\
\hline$\geq 12$ & 5 & $\mathrm{M}[32] ; \mathrm{F}[32] ;[50,51,53]$ & 0.71 & $-0.74[-1.08,-0.40]$ & 0 & $<0.0001$ & \multirow[t]{2}{*}{0.005} \\
\hline$<12$ & 5 & [33]; H [52]; L [52]; [54, 55] & 2.34 & $-2.38[-3.47,-1.29]$ & 71 & $<0.0001$ & \\
\hline \multicolumn{8}{|c|}{ RCT frequency, days/week [range 2 vs. 3.5] } \\
\hline 2 & 2 & {$[50,55]$} & 0.72 & $-0.78[-1.47,-0.09]$ & 0 & $<0.0001$ & \multirow[t]{2}{*}{0.31} \\
\hline 3 & 8 & M [32]; F [32]; [33, 51]; H [52]; L [52]; [53, 54] & 1.73 & $-1.17[-1.49,-0.85]$ & 78 & $<0.0001$ & \\
\hline \multicolumn{8}{|c|}{ Session length, min [range 20.3-35] } \\
\hline$\geq 30$ & 3 & {$[50,53,55]$} & 0.71 & $-0.76[-1.19,-0.33]$ & 0 & $<0.0001$ & \multirow[t]{2}{*}{0.03} \\
\hline$<30$ & 4 & [51]; H [52], L [52]; [54] & 1.85 & $-1.54[-2.11,-0.97]$ & 86 & $<0.0001$ & \\
\hline \multicolumn{8}{|c|}{ Methodological quality, points [range 3-7] } \\
\hline$>5$ & 5 & $\mathrm{M}[32] ; \mathrm{F}[32] ;[50,53]$ & 1.02 & $-0.92[-1.28,-0.57]$ & 0 & $<0.0001$ & \multirow[t]{2}{*}{0.08} \\
\hline$\leq 5$ & 6 & {$[33,51] ; \mathrm{H}[52] ; \mathrm{L}[52] ;[54,55]$} & 2.03 & $-1.47[-1.97,-0.96]$ & 85 & $<0.0001$ & \\
\hline
\end{tabular}

Some studies were not included because they did not report the value used for the subgroup analysis

$B M I$ body mass index, $C I$ confidence interval, $E S$ effect size, $F$ female, $H$ high, $I^{2}$ heterogeneity, $L$ low, $M$ male, $P_{\text {Difference }}$ test for subgroup differences, $p$ Value test for overall effect, SMD standardised mean difference

low intensity (<60\% 1-RM; ES: 0.90) [32, 50-53] compared with those who trained at a higher intensity $(\geq 60 \%$ 1-RM; ES: 2.08; $p=0.004$ ) [52, 54, 55] (Fig. 3b).

\subsection{One-Repetition Maximum Bench Press}

The effects of RCT on 1-RM bench press were analysed for a total of 237 participants, without any type of bias found for this variable among the published studies. The results of the overall effects on 1-RM bench press before and after RCT showed significant differences (ES: 0.92; $p<0.0001$; $\mathrm{SMD}=0.58,95 \%$ CI 0.39-0.77) [27, 32, 36, 56-60], with an average heterogeneity of $I^{2}=76 \%$ (Fig. 4a). Likewise, there were significant improvements in participants who performed RCT compared with the control groups, with high heterogeneity (ES: $1.15 ; p<0.0001 ; \mathrm{SMD}=0.94$, $95 \% \quad$ CI $\quad 0.64-1.24 ; \quad I^{2}=81 \%$ ) (Fig. 4b) $[27,32,36,56,59,60]$.

Table 2 shows the subject characteristics of the articles included in the meta-analysis for the bench press exercise [32, 36, 56-60], while the characteristics of the types of RCT and the test used for assessing maximal strength using the bench press exercise from each study are described in Table 4. There were significant differences in the 


\begin{tabular}{|c|c|c|c|c|c|c|c|c|c|c|c|c|}
\hline $\mathbf{a}$ & Post-1 & trainin & & Pre-t & training & & & Std. Mean Difference & & Std. Mean D & Difference & \\
\hline Study & Mean & SD & Total & Mean & SD & Total & Weight & IN, Fixed, $95 \% \mathrm{Cl}$ & & N, Fixed, &, $95 \% \mathrm{Cl}$ & \\
\hline 2.9.1 Number of exercis & s per se & ssion & $<10$ & & & & & & & & & \\
\hline Chtara et al. [50] & 53 & 4.05 & 9 & 50.08 & 4.89 & 9 & $9.3 \%$ & $0.62[-0.33,1.57]$ & & & & \\
\hline Haennel et al. High [52] & 36.5 & 1.6 & 8 & 32.8 & 1.8 & 8 & $5.2 \%$ & $2.05[0.78,3.33]$ & & & & \\
\hline $\begin{array}{l}\text { Haennel et al. Low [52] } \\
\text { Subtotal }(95 \% \mathrm{CI})\end{array}$ & 35.1 & 1.7 & $\begin{array}{r}8 \\
25\end{array}$ & 31.2 & 1.9 & $\begin{array}{r}8 \\
25\end{array}$ & $\begin{array}{r}5.2 \% \\
19.7 \%\end{array}$ & $\begin{array}{l}2.05[0.77,3.32] \\
1.37[0.72,2.03]\end{array}$ & & & & \\
\hline $\begin{array}{l}\text { Heterogeneity: } \mathrm{Chi}^{2}=4.5 \\
\text { Test for overall effect: } Z=\end{array}$ & $\begin{array}{l}d f=2(f \\
4.11(P<\end{array}$ & $\begin{array}{l}P=0.1 \\
0.0001\end{array}$ & $\begin{array}{l}\text { 10): }\left.\right|^{2}= \\
\text { 11) }\end{array}$ & $56 \%$ & & & & & & & & \\
\hline 2.9.2 Number of exercis & s per se & ssion & $\geq 10$ & & & & & & & & & \\
\hline Gettman et al. [51] & 41.4 & 4.5 & 11 & 40 & 4.9 & 11 & $12.0 \%$ & $0.29[-0.55,1.13]$ & & & 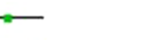 & \\
\hline Gettman et al. F [32] & 37.2 & 3.8 & 12 & 32.8 & 4.2 & 12 & $11.3 \%$ & $1.06[0.20,1.93]$ & & & & \\
\hline Gettman et al. M [32] & 45.1 & 5.5 & 14 & 40.3 & 4.2 & 14 & $13.6 \%$ & $0.95[0.16,1.74]$ & & & $\rightarrow$ & \\
\hline Kaikkonen et al. [53] & 40.4 & 4.8 & 27 & 36.6 & 5.3 & 27 & $27.7 \%$ & $0.74[0.19,1.29]$ & & & -- & \\
\hline Messier \& Dill [54] & 51.84 & 1.21 & 12 & 45.64 & 1.65 & 12 & $3.7 \%$ & $4.14[2.63,5.65]$ & & & & \\
\hline Murray et al. [55] & 54.2 & 2 & 9 & 52.2 & 2 & 9 & $8.7 \%$ & $0.95[-0.04,1.94]$ & & & & \\
\hline $\begin{array}{l}\text { Petersen et al. [33] } \\
\text { Subtotal }(95 \% \mathrm{Cl})\end{array}$ & 56.7 & 1.4 & $\begin{array}{r}8 \\
93\end{array}$ & 52.6 & 1 & $\begin{array}{r}8 \\
93\end{array}$ & $\begin{array}{r}3.3 \% \\
\mathbf{8 0 . 3} \%\end{array}$ & $\begin{array}{l}3.19[1.58,4.79] \\
\mathbf{1 . 0 3}[\mathbf{0 . 7 1}, \mathbf{1 . 3 6}]\end{array}$ & & & & \\
\hline $\begin{array}{l}\text { Heterogeneity: } \mathrm{Chi}^{2}=27 \text {. } \\
\text { Test for overall effect: } Z=\end{array}$ & $\begin{array}{l}3, d f=6 \\
6.24(P<\end{array}$ & $\begin{array}{l}(P=0 . \\
0.0000\end{array}$ & .0001); & $F^{2}=789$ & & & & & & & & \\
\hline Total $(95 \% \mathrm{Cl})$ & & & 118 & & & 118 & $100.0 \%$ & $1.10[0.81,1.39]$ & & & 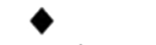 & \\
\hline $\begin{array}{l}\text { Heterogeneity: } \mathrm{Chi}^{2}=32 \text {. } \\
\text { Test for overall effect: } Z= \\
\text { Test for subaroup differe }\end{array}$ & $\begin{array}{l}2, d f=9 \\
7.42(P< \\
\text { ces: } \mathrm{Chi}^{2}\end{array}$ & $\begin{array}{l}(P=0 . \\
0.0000 \\
{ }^{2}=0.82\end{array}$ & $\begin{array}{l}\text { 0001); } \\
\text { 2. } d f=1\end{array}$ & $\begin{array}{l}I^{2}=729 \\
1(P=0 .\end{array}$ & .36). $1^{2}$ & $=0 \%$ & & & -4 & $\begin{array}{cc}1 & + \\
-2 & 0 \\
\text { Pre-training }\end{array}$ & $\begin{array}{c}\frac{1}{2} \\
\text { Post-training }\end{array}$ & 4 \\
\hline & Post. & trainin & & Pre- & trainin & & & Std. Mean Difference & & Std. Mean D & Difference & \\
\hline D study & Mean & SD & Total & Mean & SD & Total & Weight & IV, Fixed, $95 \% \mathrm{Cl}$ & & IV, Fixed, & $1,95 \% \mathrm{Cl}$ & \\
\hline 2.6.1 Low intensity $<60$ & & & & & & & & & & & & \\
\hline Chtara et al. [50] & 53 & 4.05 & 9 & 50.08 & 4.89 & 9 & $9.7 \%$ & $0.62[-0.33,1.57]$ & & & & \\
\hline Gettman et al. [51] & 41.4 & 4.5 & 11 & 40 & 4.9 & 11 & $12.4 \%$ & $0.29[-0.55,1.13]$ & & & & \\
\hline Gettman et al. F [32] & 37.2 & 3.8 & 12 & 32.8 & 4.2 & 12 & $11.7 \%$ & $1.06[0.20,1.93]$ & & & & \\
\hline Gettman et al. M [32] & 45.1 & 5.5 & 14 & 40.3 & 4.2 & 14 & $14.1 \%$ & $0.95[0.16,1.74]$ & & & & \\
\hline Haennel et al. Low [52] & 35.1 & 1.7 & 8 & 31.2 & 1.9 & 8 & $5.4 \%$ & $2.05[0.77,3.32]$ & & & & \\
\hline $\begin{array}{l}\text { Kaikkonen et al. [53] } \\
\text { Subtotal (95\% Cl) }\end{array}$ & 40.4 & 4.8 & $\begin{array}{l}27 \\
81\end{array}$ & 36.6 & 5.3 & $\begin{array}{l}27 \\
81\end{array}$ & $\begin{array}{l}28.6 \% \\
\mathbf{8 1 . 8} \%\end{array}$ & $\begin{array}{l}0.74[0.19,1.29] \\
0.83[0.50,1.15]\end{array}$ & & & -1 & \\
\hline $\begin{array}{l}\text { Heterogeneity: } \mathrm{Chi}^{2}=5.7 \\
\text { Test for overall effect: } Z=\end{array}$ & $\begin{array}{l}5, d f=5( \\
4.95(P=\end{array}$ & $\begin{array}{l}(P=0.3 \\
<0.000\end{array}$ & $\begin{array}{l}\text { 33); }\left.\right|^{2}= \\
\text { j01) }\end{array}$ & $=13 \%$ & & & & & & & & \\
\hline 2.6.3 High intensity $\geq 60$ & & & & & & & & & & & & \\
\hline Haennel et al. High [52] & 36.5 & 1.6 & 8 & 32.8 & 1.8 & 8 & $5.4 \%$ & $2.05[0.78,3.33]$ & & & & \\
\hline Messier \& Dill [54] & 51.84 & 1.21 & 12 & 45.64 & 1.65 & 12 & $3.8 \%$ & $4.14[2.63,5.65]$ & & & & \\
\hline $\begin{array}{l}\text { Murray et al. [55] } \\
\text { Subtotal }(95 \% \mathrm{Cl})\end{array}$ & 54.2 & 2 & $\begin{array}{r}9 \\
29\end{array}$ & 52.2 & 2 & $\begin{array}{r}9 \\
29\end{array}$ & $\begin{array}{r}9.0 \% \\
18.2 \%\end{array}$ & $\begin{array}{l}0.95[-0.04,1.94] \\
1.95[1.26,2.65]\end{array}$ & & & & \\
\hline $\begin{array}{l}\text { Heterogeneity: } \mathrm{Chi}^{2}=12 \\
\text { Test for overall effect: } Z=\end{array}$ & $\begin{array}{l}0, d f=2 \\
5.51(P<\end{array}$ & $\begin{array}{l}(P=0 \\
\alpha 0.000\end{array}$ & $\begin{array}{l}0.002) ; 1 \\
001)\end{array}$ & $I^{2}=83 \%$ & & & & & & & & \\
\hline Total $(95 \% \mathrm{Cl})$ & & & 110 & & & 110 & $100.0 \%$ & $1.03[0.73,1.33]$ & & & & \\
\hline $\begin{array}{l}\text { Heterogeneity: } \mathrm{Chi}^{2}=26 \\
\text { Test for overall effect: } Z= \\
\text { Test for subaroun differe }\end{array}$ & $\begin{array}{l}\text { 11, } d f=8 \\
6.82(P< \\
\text { aces: } C h i\end{array}$ & $\begin{array}{l}(P=0 . \\
<0.000 \\
i^{2}=8.2\end{array}$ & $\begin{array}{l}\text { 001); } 1 \\
\text { 27. } d f=\end{array}$ & $\begin{array}{l}F^{2}=69 \% \\
1(P=0\end{array}$ & & & & & -4 & $\begin{array}{c}-2 \\
-2 \\
\text { Pre-training }\end{array}$ & $\begin{array}{l}0 \\
0 \\
\text { Post-training }\end{array}$ & 4 \\
\hline
\end{tabular}

Fig. 3 Differences in maximum oxygen uptake $\left(\mathrm{VO}_{2 \max }\right)[\mathrm{mL} / \mathrm{kg} /$ $\mathrm{min}$ ] improvement after a training programme as a function of a the number of exercises per session and $\mathbf{b}$ the intensity. $C I$ confidence interval, $F$ female, $H$ high, $I V$ inverse variance, $L$ low, $M$ male, $S D$ standard deviation, Std standardised

active $=0.58[32,57-60]$; healthy trained $=0.99$ [27]; $p=0.0008)[$ ES: men $=0.78[32,36,55,61,63-65]$; women $=2.32 \quad[36,55] ; \quad$ and $\operatorname{mixed}=0.16 \quad[62]$; $p=0.002)$. When the training factors were analysed, greater changes were found in the workout sessions $<60 \mathrm{~min}$ compared with those who exercised $\geq 60 \min (\mathrm{ES}:<60 \mathrm{~min}=1.27 \quad[36,56,59] ; \geq$ $60 \min =0.41[27,57,58] ; p=0.01)$. Last, there were statistically significant differences in the different training 


\begin{tabular}{|c|c|c|c|c|c|c|c|}
\hline \multirow[b]{2}{*}{ Study } & \multicolumn{3}{|c|}{ Post-training } & \multicolumn{3}{|c|}{ Pre-training } & \multirow[b]{2}{*}{ Weight } \\
\hline & Mean & SD & Total & Mean & SD & Total & \\
\hline Alcaraz et al. [27] & 112.34 & 20.48 & 15 & 92.81 & 18.61 & 15 & $6.2 \%$ \\
\hline Camargo et al. [56] & 56.9 & 12.03 & 7 & 50.27 & 10.5 & 7 & $3.1 \%$ \\
\hline Dorgo et al. MRT [57] & 66.1 & 32.1 & 53 & 61.6 & 34.3 & 53 & $24.9 \%$ \\
\hline Dorgo et al. RCT [57] & 73.9 & 31.8 & 31 & 67.3 & 33.2 & 31 & $14.5 \%$ \\
\hline Esquivel \& Wellsch RCT 1 [58] & 71.97 & 37.42 & 15 & 60.93 & 32.62 & 15 & $7.0 \%$ \\
\hline Esquivel \& Wellsch RCT 2 [58] & 70.91 & 38.41 & 20 & 56 & 35.97 & 20 & $9.2 \%$ \\
\hline Gettman et al. F [32] & 36 & 9 & 12 & 30 & 7 & 12 & $5.2 \%$ \\
\hline Gettman et al. M [32] & 75 & 13 & 14 & 66 & 11 & 14 & $6.1 \%$ \\
\hline Mate-Muñoz et al. RCT [59] & 82.3 & 16.93 & 10 & 78.8 & 16.2 & 10 & $4.7 \%$ \\
\hline Mate-Muñoz et al. UCT [59] & 81.17 & 9.65 & 12 & 77.5 & 8.22 & 12 & $5.5 \%$ \\
\hline Rahmania et al. [60] & 75.78 & 4.88 & 20 & 66.5 & 4.54 & 20 & $6.2 \%$ \\
\hline Wilmore et al M [36] & 69.58 & 3.58 & 16 & 64.22 & 3.7 & 16 & $5.8 \%$ \\
\hline Wilmore et al. F [36] & 37.78 & 1.17 & 12 & 31.43 & 1.54 & 12 & $1.4 \%$ \\
\hline Total $(95 \% \mathrm{Cl})$ & & & 237 & & & 237 & $100.0 \%$ \\
\hline
\end{tabular}

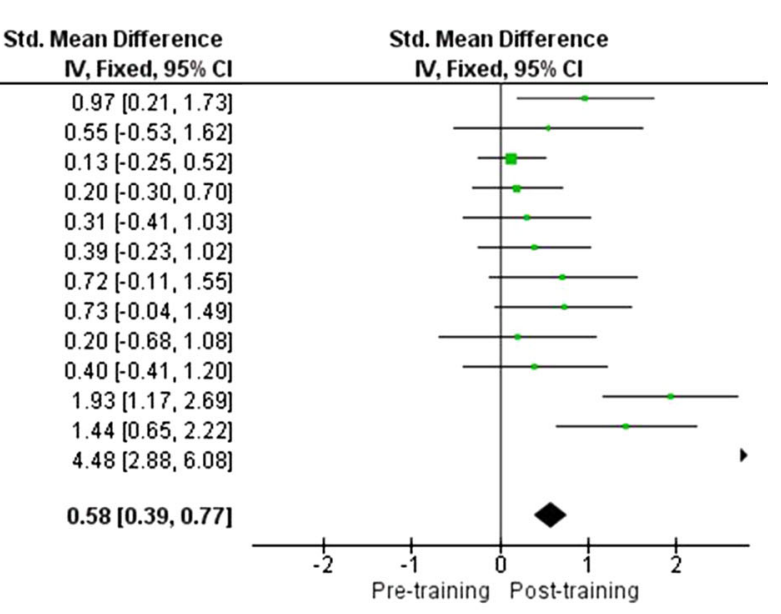

\begin{tabular}{|c|c|c|c|c|c|c|c|}
\hline \multirow{2}{*}{ Study } & \multicolumn{3}{|c|}{ Experimental Group } & \multicolumn{3}{|c|}{ Control Group } & \multirow[b]{2}{*}{ Weight } \\
\hline & Mean & SD & Total & Mean & SD & Total & \\
\hline Alcaraz et al. [27] & 112.34 & 20.48 & 15 & 85.18 & 19.34 & 7 & $9.1 \%$ \\
\hline Camargo et al. [56] & 56.9 & 12.03 & 7 & 39.05 & 14.98 & 7 & $6.4 \%$ \\
\hline Gettman et al. F [32] & 36 & 9 & 12 & 33 & 3 & 12 & $13.5 \%$ \\
\hline Gettman et al. M [32] & 75 & 13 & 14 & 72 & 13 & 14 & $16.1 \%$ \\
\hline Mate-Muñoz et al. RCT [59] & 82.3 & 16.93 & 10 & 81 & 18.84 & 12 & $12.6 \%$ \\
\hline Mate-Muñoz et al. UCT [59] & 81.17 & 9.65 & 12 & 81 & 18.84 & 12 & $13.9 \%$ \\
\hline Rahmania et al. [60] & 75.78 & 4.88 & 20 & 64.75 & 4.52 & 20 & $13.4 \%$ \\
\hline Wilmore et al M [36] & 69.58 & 3.58 & 16 & 62 & 5.76 & 10 & $10.4 \%$ \\
\hline Wilmore et al. F [36] & 37.78 & 1.17 & 12 & 32.65 & 1.58 & 11 & $4.5 \%$ \\
\hline Total $(95 \% \mathrm{Cl})$ & & & 118 & & & 105 & $100.0 \%$ \\
\hline
\end{tabular}

Fig. 4 Total effects of resistance circuit-based training (RCT) on one-repetition maximum (1-RM) bench press $(\mathrm{kg})$ : a pre- vs. posttraining; and b control group vs. RCT. CI confidence interval,

intensities (ES: $\geq 60 \% 1-\mathrm{RM}=0.56[27,56-58] ;<60 \%$ $1-\mathrm{RM}=1.75 ; p=0.001 \quad[32,36,60]$ ) (Fig. 5b). With regard to the methodological quality of the studies, there were no significant differences between those with a score of $\geq 6$ or higher $[27,32,56,60]$ or $<6[36,57-59]$ on the PEDro scale.

\section{Discussion}

The main objectives of this meta-analysis were to assess the effects of RCT on $\mathrm{VO}_{2 \max }$ and 1-RM bench press in healthy adults, as well as to analyse which training characteristics had a greater effect. The principal finding was that RCT had an overall significant and large effect on $\mathrm{VO}_{2 \max }$ (average of $\sim 9.7 \%$ ), demonstrating that this training modality increases $\mathrm{VO}_{2 \max }$, independent of the protocol used in the studies. Additionally, the meta-analysis showed that RCT had an overall significant and large effect on 1-RM bench press (average of $\sim 13.2 \%$ ). However, its effect appears to be influenced by population and training characteristics.

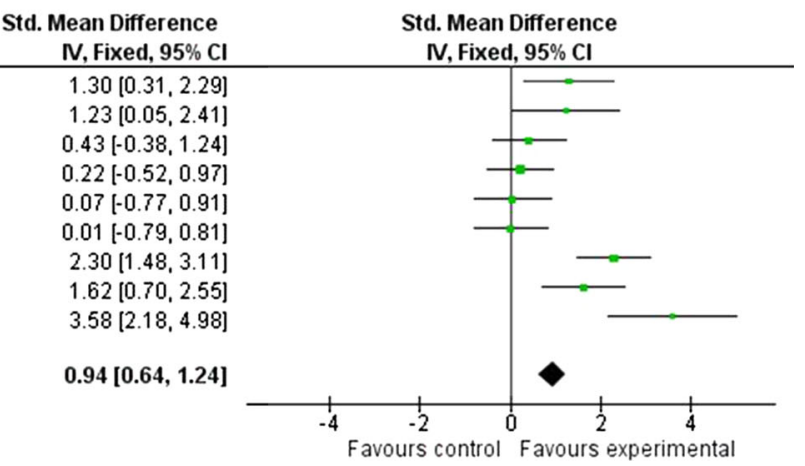

$F$ female, $H$ high, $I V$ inverse variance, $L$ low, $M$ male, $M R T$ manual resistance training, $S D$ standard deviation, Std standardised, $U C T$ unstable circuit training

\subsection{Maximum Oxygen Uptake}

As mentioned, RCT is an effective training method for the development of $\mathrm{VO}_{2 \max }$ in healthy adults, independent of their age, sex, BMI or level of training. It should be noted that for the results of the time effect of RCT on $\mathrm{VO}_{2 \max }$, there were significant differences in all the groups analysed. The same can be said when comparing the studies that included experimental vs. control groups $[32,33,50-53]$. Despite the fact that some studies found that strength training was an inadequate means of increasing $\mathrm{VO}_{2 \max }[30,36]$, probably owing to the training protocols used (the study by Hurley et al. [30], for example, was not included in the analysis because it did not meet the inclusion criteria with regard to study protocols), the present meta-analysis clearly shows that resistance circuitbased training can improve aerobic capacity.

Bassett and Howley [21] described how a normal range of $\mathrm{VO}_{2 \max }$ observed in sedentary and trained men and women of the same age is owing mainly to a variation in maximal stroke volume. Some investigations have shown that $\mathrm{VO}_{2 \max }$, maximal stroke volume and cardiac output 
Table 6 Subgroup analyses assessing potential moderating factors of one repetition maximum bench press in studies included in the metaanalysis

\begin{tabular}{|c|c|c|c|c|c|c|c|}
\hline \multirow[t]{2}{*}{ Group } & \multirow{2}{*}{$\begin{array}{l}\text { Circuit } \\
\text { training } \\
\text { group }(n)\end{array}$} & \multirow[t]{2}{*}{ Studies } & \multicolumn{5}{|c|}{ Increase in $\mathrm{kg}$} \\
\hline & & & $\overline{\mathrm{ES}}$ & $\begin{array}{l}\text { SMD } \\
(95 \% \mathrm{CI})\end{array}$ & $I^{2}$ & $p$ Value & $P_{\text {Difference }}$ \\
\hline \multicolumn{8}{|c|}{ Population characteristics } \\
\hline \multicolumn{8}{|c|}{ Age, years [range 21-35.9] } \\
\hline$\geq 22.7$ & 6 & [27]; M [32]; F [32]; [56]; MRT [57]; RCT [57] & 0.71 & $-0.69[-1.00,0.39]$ & 65 & $<0.0001$ & \multirow[t]{2}{*}{0.05} \\
\hline$<22.7$ & 5 & RCT_1 [58]; RCT_2 [58]; RCT [59]; UCT [59]; [60] & 0.49 & $-0.30[-0.56,-0.04]$ & 0 & 0.02 & \\
\hline \multicolumn{8}{|c|}{ BMI, $\mathrm{kg} / \mathrm{m}^{2}$ [range $22.6-27.9$ ] } \\
\hline$\leq 25$ & 6 & [27]; M [36]; F [36]; RCT [59]; UCT [59]; [60] & 1.46 & $-1.20[-1.55,-0.85]$ & 83 & $<0.0001$ & \multirow[t]{2}{*}{0.0001} \\
\hline$>25$ & 7 & $\begin{array}{l}\text { M [32]; F [32]; [56]; MRT [57]; RCT [57]; RCT_1 } \\
\text { [58]; RCT_2[58] }\end{array}$ & 0.45 & $-0.31[-0.54,-0.09]$ & 0 & 0.007 & \\
\hline \multicolumn{8}{|l|}{ Sex } \\
\hline M & 9 & $\begin{array}{l}\text { [27]; M [32]; M [36]; [56]; RCT_1 [58]; RCT_2 [58]; } \\
\text { RCT [59]; UCT [59]; [60] }\end{array}$ & 0.78 & $-0.77[-1.03,-0.51]$ & 54 & $<0.0001$ & \multirow[t]{3}{*}{0.002} \\
\hline $\mathrm{F}$ & 2 & $\mathrm{~F}[32] ; \mathrm{F}[36]$ & 2.32 & $-1.52[-2.25,-0.78]$ & 94 & $<0.0001$ & \\
\hline Mixed & 2 & MRT [57]; RCT [57] & 0.16 & $-0.16[-0.46,0.14]$ & 0 & 0.3 & \\
\hline \multicolumn{8}{|l|}{ Fitness level } \\
\hline Sedentary & 3 & F [36]; M [36]; [56] & 1.92 & $-1.58[-2.17,-0.99]$ & 88 & $<0.0001$ & \multirow[t]{3}{*}{0.0008} \\
\hline Active & 9 & $\begin{array}{l}\text { M [32]; F [32]; MRT [57]; RCT [57]; RCT_1 [58]; } \\
\text { RCT_2 [58]; RCT [59]; UCT [59]; [60] }\end{array}$ & 0.58 & $-0.42[-0.63,-0.22]$ & 59 & $<0.0001$ & \\
\hline Trained & 1 & {$[27]$} & 0.99 & $-0.97[-1.73,-0.21]$ & - & 0.01 & \\
\hline \multicolumn{8}{|c|}{ Exercise characteristics } \\
\hline \multicolumn{8}{|c|}{ Number of sessions [range 15-42] } \\
\hline$\geq 30$ & 7 & $\begin{array}{l}\text { M [32]; F [32]; M [36]; F [36]; [56]; MRT [57]; RCT } \\
\text { [57] }\end{array}$ & 0.64 & $-0.50[-0.75,-0.26]$ & 83 & $<0.0001$ & \multirow[t]{2}{*}{0.34} \\
\hline$<30$ & 6 & $\begin{array}{l}\text { [27]; RCT_1 [58]; RCT_2 [58]; RCT [59]; UCT [59]; } \\
\text { [60] }\end{array}$ & 0.71 & $-0.69[-1.00,-0.39]$ & 65 & $<0.0001$ & \\
\hline \multicolumn{8}{|c|}{ Duration, weeks [range 5-14] } \\
\hline$\geq 10$ & 7 & $\begin{array}{l}\text { M [32]; F [32]; M [36]; F [36]; [56]; MRT [57]; RCT } \\
\text { [57] }\end{array}$ & 0.64 & $-0.50[-0.75,-0.26]$ & 83 & $<0.0001$ & \multirow[t]{2}{*}{0.34} \\
\hline$<10$ & 6 & $\begin{array}{l}\text { [27]; RCT_1 [58]; RCT_2 [58]; RCT [59]; UCT [59]; } \\
\text { [60] }\end{array}$ & 0.71 & $-0.69[-1.00,-0.39]$ & 65 & $<0.0001$ & \\
\hline \multicolumn{8}{|c|}{ Session length, min [range $22.5-78$ ] } \\
\hline$\geq 60$ & 5 & [27]; MRT [57]; RCT [57]; RCT_1 [58]; RCT_2 [58] & 0.41 & $-0.29[-0.53,-0.05]$ & 0 & 0.02 & \multirow[t]{2}{*}{0.01} \\
\hline$<60$ & 5 & [56]; RCT [59]; UCT [59]; M [36]; F [36] & 1.27 & $-0.89[-1.29,-0.49]$ & 85 & $<0.0001$ & \\
\hline \multicolumn{8}{|c|}{ PEDro scale, points [range 4-9] } \\
\hline$\geq 6$ & 5 & [27]; M [32]; F [32]; [56]; [60] & 0.71 & $-1.04[-1.40,-0.67]$ & 45 & $<0.0001$ & \multirow[t]{2}{*}{0.004} \\
\hline$<6$ & 8 & $\begin{array}{l}\text { M [36]; F [36]; MRT [57]; RCT [57]; RCT_1 [58]; } \\
\text { RCT_2 [58]; RCT [59]; UCT [59] }\end{array}$ & 0.53 & $-0.41[-0.63,-0.19]$ & 80 & $<0.0001$ & \\
\hline
\end{tabular}

Some studies were not included because they did not report the value used for subgroup analysis

$B M I$ body mass index, $C I$ confidence interval, $E S$ effect size, $F$ female, $I^{2}$ heterogeneity, $M$ male, $M R T$ manual resistance training, $P_{\text {Difference }}$ test for subgroup differences, $p$ Value test for overall effect, $R C T$ resistance circuit-based training, $S M D$ standardised median difference, $U C T$ unstable circuit training

of previously trained subjects increased by $8 \%$ with RCT [33]. Similarly, Haennel et al. [52] concluded that the main responses of the cardiovascular system to RCT included a significant increase in $\mathrm{VO}_{2 \max }$, together with a maximal stroke volume and maximal cardiac output. However, analysis of the RCT programmes showed that some of the changes observed in $\mathrm{VO}_{2 \max }$ may be explained to some extent by body composition, as well. It should be noted that lean body mass is highly correlated with $\mathrm{VO}_{2 \max }$ [61], and other RCT studies have shown an increase in lean mass $[32,51,55]$. Therefore, expressing $\mathrm{VO}_{2 \max }$ relative to lean mass as opposed to total body mass could provide a clearer interpretation of the results [26]. 
$\mathbf{a}$

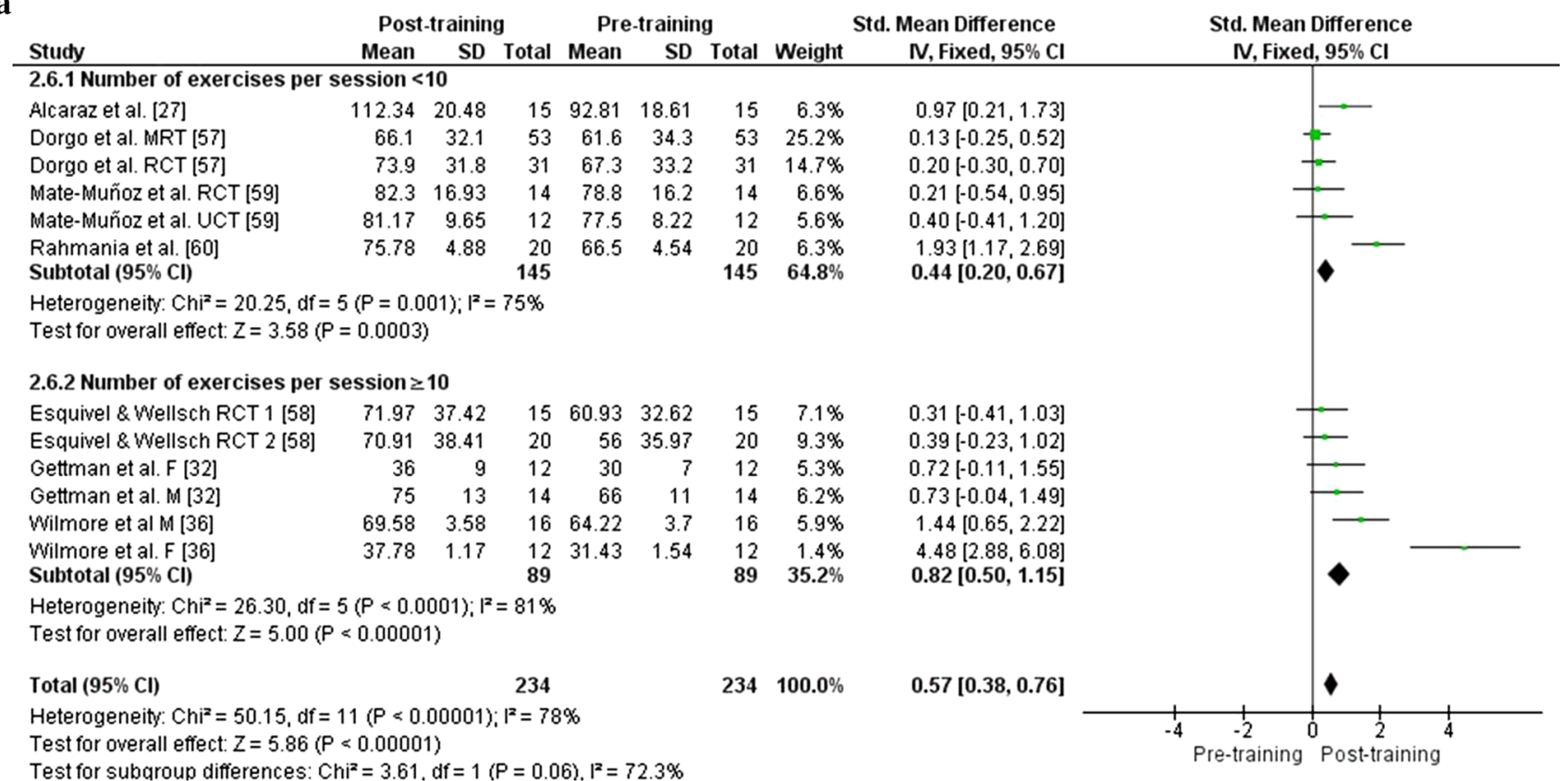

b

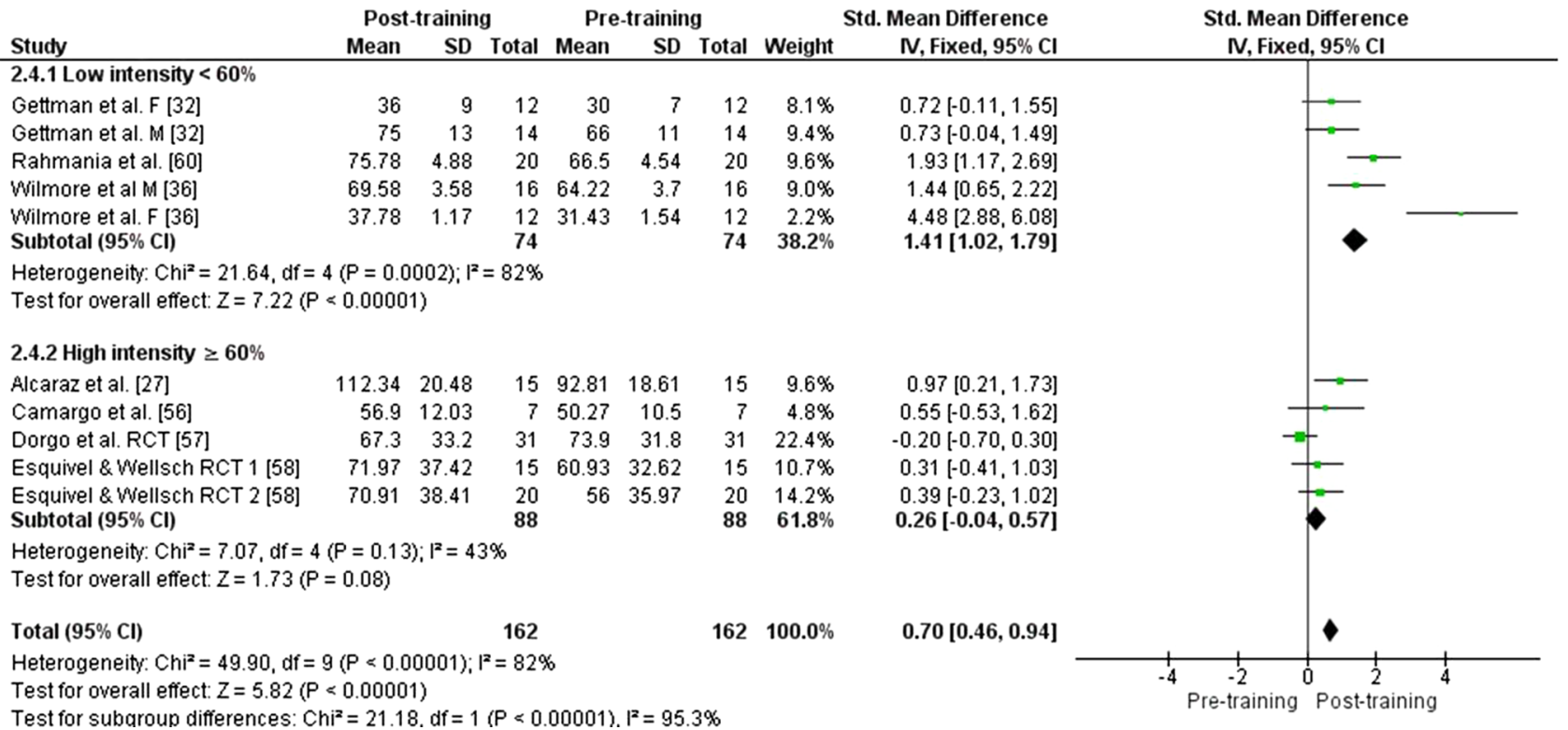

Fig. 5 Differences in one-repetition maximum (1-RM) bench press $(\mathrm{kg})$ improvement after a training programme as a function of (a) the number of exercises per session and (b) the intensity. CI confidence

Interestingly, no significant differences were observed when age was taken into account. In addition, no significant differences were found when considering sex as a potential factor, as only two studies included women: one included only women [32] and the other both sexes [53]. The few studies that have included women are insufficient to make a significant comparison, as there were eight training groups that included only men $[32,33,50-52,54,55]$. Furthermore, there were no interval, $F$ female, $H$ high, $I V$ inverse variance, $L$ low, $M$ male, $M R T$ manual resistance training, $R C T$ resistance circuit-based training, $U C T$ unstable circuit training, $S D$ standard deviation, Std standardised

changes observed with regard to the different levels of physical activity. There was only one group of sedentary participants [53], two groups of trained participants $[33,51]$ and seven groups of healthy active participants $[32,50,52,54,55]$, making it difficult to make an adequate comparison.

Importantly, this meta-analysis shows that RCT increases $\mathrm{VO}_{2 \max }$ but also shows that careful manipulation of the variables that determine training load could further 
intensify $\mathrm{VO}_{2 \max }$ adaptations. However, there was a large heterogeneity between the RCT protocols performed among the articles included in this meta-analysis that examined $\mathrm{VO}_{2 \max }$. For example, the intensity levels expressed as a percentage of 1-RM varied from 20 to $93 \%$. The duration of the different protocols ranged from 6 to 20 weeks of training, with a weekly frequency of 2-3.5 sessions. The total number of sessions fluctuated between 14 and 60, and the session duration varied between 20.3 and $35 \mathrm{~min}$, consisting of a total of 6-12 exercises per sessions, $12-15$ repetitions or $20-40$ s of work per station, and two circuit sets.

Taking this into account, the greatest changes in $\mathrm{VO}_{2 \max }$ were observed when examining the training protocol characteristics. Significant differences in session duration were observed (30 min or longer $[50,53,55]$ vs. less than 30 min $[51,52,54])$. Groups that had a shorter session duration experienced a two-fold greater improvement in $\mathrm{VO}_{2 \max }$ than groups that had a longer session duration. However, this result should be interpreted with caution, as only one study had sessions that lasted longer than $30 \mathrm{~min}$, reaching $35 \mathrm{~min}$ per session [55]. Furthermore, there was only one study that was moderately shorter than $30 \mathrm{~min}$ per session, stopping at $20.3 \mathrm{~min}$ [54]. The remaining studies had a homogeneous range of $26.5-30 \mathrm{~min}$ per session [50-53]. Likewise, when taking into account the total number of weeks (and their corresponding total number of sessions), there was up to a three-fold greater effect (very large vs. medium ES) in groups with protocols of $<12$ weeks' duration [33, 52, 54, 55] compared with those $\geq 12$ weeks $[32,50,51,53]$.

These findings are in agreement with previous studies that have reported that the optimal duration for improvements in $\mathrm{VO}_{2 \max }$ with RCT is $10-12$ weeks $[30,37,50]$. One possible cause could be that vascular adaptations may not occur until there is evidence of a change in muscle mass [58]. Nonetheless, it should be noted that only one study assessed 20 weeks of training [51], while the rest ranged from 6 to 12 weeks. Thus, these differences should also be interpreted with caution because the 12-week point may not be a key duration that was determined after examination of the improvement-training duration relationship, but rather was chosen simply to compare studies. Additionally, weekly training frequency (3 days $[32,33,51-54]$ vs. 2 days $[50,55])$ was associated with a similar pattern of improvements as observed with the total number of weeks of training. However, only three out of the ten groups studied had a frequency that was not 3 days, but $2[50,55]$ and 3.5 [33] weekly sessions.

Regarding the training intensity and the number of sets performed, there was a two-fold greater effect (very large vs. medium ES) with a high-intensity [52, 54, 55] compared with a low-intensity circuit training [32, 50-53]. Specifically, it should be mentioned that the studies that included high-intensity training ranged between 67 and 93\% 1-RM; therefore, the optimal intensity was difficult to establish, although an intensity progression starting at $60 \%$ of $1-\mathrm{RM}$ and finishing at $90 \%$ of $1-\mathrm{RM}$ may be more ideal. This training plan may be explained by the suggestion by some authors [51] who have indicated that any change in $\mathrm{VO}_{2 \max }$ resulting from RCT may be the result of increases in lean body mass. It should be noted that these intensities (70-90\% of 1-RM) are the optimal for increases in muscle mass. Another reason for the observed greater improvements associated with highintensity RCT is that it allowed individuals to work closer to their $\mathrm{VO}_{2 \max }$, resulting in a significant increase in $\mathrm{VO}_{2}$ at the second ventilatory threshold [50].

\subsection{One-Repetition Maximum Bench Press}

There was an overall significant and large pre-post effect of resistance circuit-based training on the upper-body maximal strength measured via 1-RM bench press, as well as between experimental and control groups $[27,32,36,56,59,60]$. One of the main reasons for these improvements was the increase in lean body mass in the majority of the selected studies $[27,32,36,56]$. These studies showed that lean body mass increased significantly (from $\sim 0.6$ to $\sim 1.9 \mathrm{~kg}$ ). In future reviews, it could be interesting to analyse the effects of RCT on body composition.

After evaluating the studies that examined 1-RM bench press, diverse resistance circuit-based training protocols that provoked significant changes in maximal strength were found. Studies used a range of intensities for training based on the percentage of 1-RM (from 30 to $90 \%$ ). The duration of the different protocols varied between 5 and 14 weeks of training, with a weekly frequency of three sessions. The total number of sessions differed between 15 and 42, and the session duration ranged from 22.5 to $78 \mathrm{~min}$. A total of 6-17 exercises per session with 6-15 repetitions or $30 \mathrm{~s}$ of work per station, completing two to six sets in the circuit, were observed. Based on the meta-analysis, changes in bench press values were in some cases determined by the participant's characteristics. For example, RCT had a greater effect on participants with a lower $\left(\leq 25 \mathrm{~kg} / \mathrm{m}^{2}\right)$ BMI $[27,36,59,60](\mathrm{ES}=1.46)$ than those who had a higher BMI $(\mathrm{ES}=0.45)[32,56-58]$ (large vs. small ES). It seems that recreationally trained, healthy adult men with low-strength levels have lower BMI when compared with their high-strength levels counterpart [62]. Therefore, the adaptations could be higher in these participants. Additionally, sex and fitness level were observed to have an overall effect on 1-RM bench press. This means that RCT could be more beneficial for women and sedentary participants in the development of maximal strength, while men and trained participants probably need a higher training 
intensity to increase the 1-RM bench press [36]. In fact, the strength level prior to training was typically low in those studies that used lower loads to elicit significant increases in strength, whereas the initial strength level of participants tended to be higher in studies where higher loads were used $[27,58]$. Either way, the interpretation of these results should be made cautiously, as there is a lack of consistency between subgroups with regard to the number of studies and the observed high heterogeneity values.

In relation to the fitness level, there were significant differences between previously sedentary participants compared with those who were previously active or strength trained prior to circuit-based training. There was a three-fold greater effect (large vs. small ES) in sedentary individuals compared with active individuals, and a twofold greater effect (large vs. moderate ES) vs. previously trained participants following RCT. This conclusion is contrary to that of Gettman et al. [51], who examined individual improvements in strength for each training group and found that those subjects who had a lower strength initially improved as much as those who had higher strength on the bench press test. However, in our study, it should be noted that there was only one group that consisted of individuals with strength-training experience [27], while there were three sedentary groups $[36,56]$ and nine active groups [32, 57-60].

Interestingly, there appear to be certain training characteristics that are responsible for maximal strength development in the bench press. There was a significant three-fold greater effect (large vs. small ES) in groups using low-intensity $[32,36,60]$ compared with high-intensity $[27,56-58]$ training protocols. However, because of the lack of homogeneity between the low-intensity groups used for establishing the comparison, this finding should be treated with caution. As mentioned above, the observed differences could be owing to the different methodology used and the different populations included in the studies. Similarly, there was a significant three-fold greater effect (large vs. small ES) in studies with training sessions that lasted $<60 \mathrm{~min}$ [36, 56, 59] compared with $\geq 60 \mathrm{~min}$ $[27,57,58]$. However, this finding should also be taken with caution because of the lack of homogeneity among the groups that improved the most. As for the other training characteristics, such as the total number of sessions $(<30$ $[27,58-60]$ and $\geq 30[32,36,56,57])$ and the number of training weeks $(<10[27,58-60]$ and $\geq 10[32,36,56,57])$, no significant differences were found between groups (moderate ES in both cases). In this regard, only one study in the analysis used a greater number of sessions, up to 42 , which also coincided with being the only study that went beyond 12 weeks of training [57]. It is apparent that RCT, even in sessions lasting $22.5-60 \mathrm{~min}$ for 6-12 weeks, provokes large adaptations; however, there is insufficient evidence to support that longer training sessions/periods provide an additional benefit.

\subsection{Limitations and Future Research}

A limitation of this systematic review with a meta-analysis is that we included studies in which only bench press strength was examined. Therefore, to achieve a more comprehensive picture, future studies should include lower body exercises (particularly as smaller muscle/upper body strength may vary more between sexes and other populations than larger muscle/lower body strength). Although there is evidence, which supports the existence of an endurance training interference effect on resistance training-induced muscle hypertrophy and strength, the mechanisms that induce this effect have not been clarified. The various signalling pathways involved in endurance- and resistance/strength-based adaptations are numerous and have been reviewed in detail elsewhere [63, 64]. Importantly, the specificity of the molecular training responses with divergent exercise modes and the time course over which these events occur provide the essential context in which concurrent training adaptation and performance outcomes should be evaluated [65]. Accordingly, future studies should identify the mechanisms related to the improvements in $\mathrm{VO}_{2 \max }$ (i.e. cardiovascular, metabolic and molecular adaptations) and 1-RM bench press (i.e. neuromuscular and structural adaptations) after RCT. Additionally, to provide a more complete review and broader picture for clinicians, systematic reviews with meta-analysis that compare RCT with strength training only and/or aerobic training only are necessary. Without these comparisons, it is not possible to truly determine the effect of RCT.

\section{Conclusions}

This systematic review with a meta-analysis concludes that resistance circuit-based training can greatly increase $\mathrm{VO}_{2}$ max (average of $\sim 9.7 \%$ ) and 1-RM bench press (average of $\sim 13.2 \%$ ) in healthy adults, independent of the protocol used in the studies. Based on the characteristics of the population and noting that there were no significant differences between groups, greater effects on $\mathrm{VO}_{2 \max }$ were observed after RCT in recreationally active men. Regarding the 1-RM bench press, greater significant effects on maximal strength of the upper limbs were also observed after RCT in women, in sedentary individuals, and those with a BMI $\leq 25 \mathrm{~kg} / \mathrm{m}^{2}$.

Although there is continuous debate regarding the effects produced by RCT, the present article presents key information concerning the specific characteristics of 
training that could produce benefits in sedentary healthy populations, as well as active and/or trained populations. Thus, for greater effects on $\mathrm{VO}_{2 \max }$, the RCT programme should have a total volume of $\sim 14-30$ training sessions (total range: 14-60 sessions), a duration of $\sim 6-12$ weeks (total range 6-20 weeks), a weekly frequency of 2-3 days/ week, an intensity that progresses from $\sim 60$ to $90 \% 1$ 1-RM (total range 20-93\% 1-RM), and last between $\sim 20$ and 30 min (total range 20-35 min) per session.

However, for greater effects on 1-RM bench press, the RCT should be composed of $\sim 30$ training sessions (total range: $15-42$ sessions), have a duration of $\sim 10$ weeks (total range: 5-14 weeks), a weekly frequency of 3 days/ week, an intensity progressing from $\sim 30$ to $60 \% 1$-RM (total range: 30-90\% 1-RM), and sessions lasting at least $\sim 22.5-60 \mathrm{~min}$ (total range 22.5-78 $\mathrm{min}$ ). However, with respect to the latter recommendation, while the data indicate that $1-\mathrm{RM}$ bench press increases more when lighter intensities $(<60 \%$ 1-RM) are used, this finding can be explained by the differences in participants' baseline fitness level [being lower in those who participated in lighter load circuit training studies, but higher ( 60-90\% 1-RM) in the two studies with resistance-trained participants in which the highest percentage gains of 1-RM bench press were observed]. Therefore, more evidence about the optimal intensity is needed in relation to use of RCT to improve 1-RM bench press in trained individuals.

\section{Compliance with Ethical Standards}

Funding No sources of funding were used to assist in the preparation of this article.

Conflict of Interest Francisco Antonio Muñoz-Martínez, Jacobo Á. Rubio-Arias, Domingo Jesús Ramos-Campo and Pedro E. Alcaraz have no conflicts of interest directly relevant to the content of this review.

\section{References}

1. Buchheit M, Laursen PB. High-intensity interval training, solutions to the programming puzzle. Part I: cardiopulmonary emphasis. Sports Med. 2013;43(5):313-38.

2. Buchheit M, Laursen PB. High-intensity interval training, solutions to the programming puzzle. Part II: anaerobic energy, neuromuscular load and practical applications. Sports Med. 2013;43(10):927-54.

3. Ferrari Bravo D, Impellizzeri FM, Rampinini E, et al. Sprint vs. interval training in football. Int J Sports Med. 2008;29(8):668-74.

4. Silva JR, Nassis GP, Rebelo A. Strength training in soccer with a specific focus on highly trained players. Sports Med Open. 2015;1(1): 17

5. Hoff J, Helgerud J. Endurance and strength training for soccer players: physiological considerations. Sports Med. 2004;34(3):165-80.

6. Cormie P, McGuigan MR, Newton RU. Developing maximal neuromuscular power. Part 1: biological basis of maximal power production. Sports Med. 2011;41(1):17-38.
7. de Lacey J, Brughelli M, McGuigan M, et al. The effects of tapering on power-force-velocity profiling and jump performance in professional rugby league players. J Strength Cond Res. 2014;28(12):3567-70.

8. Hartmann H, Wirth K, Keiner M, et al. Short-term periodization models: effects on strength and speed-strength performance. Sports Med. 2015;45(10):1373-86.

9. Haugen T, Tonnessen E, Oksenholt O, et al. Sprint conditioning of junior soccer players: effects of training intensity and technique supervision. PLoS One. 2015;10(3):e0121827.

10. Marwick TH, Hordern MD, Miller T, et al. Exercise training for type 2 diabetes mellitus: impact on cardiovascular risk: a scientific statement from the American Heart Association. Circulation. 2009;119(25):3244-62.

11. Haskell WL, Lee IM, Pate RR, et al. Physical activity and public health: updated recommendation for adults from the American College of Sports Medicine and the American Heart Association. Med Sci Sports Exerc. 2007;39(8):1423-34.

12. Garber CE, Blissmer B, Deschenes MR, et al. American College of Sports Medicine position stand. Quantity and quality of exercise for developing and maintaining cardiorespiratory, musculoskeletal, and neuromotor fitness in apparently healthy adults: guidance for prescribing exercise. Med Sci Sports Exerc. 2011;43(7):1334-59.

13. Colberg SR, Sigal RJ, Fernhall B, et al. Exercise and type 2 diabetes: the American College of Sports Medicine and the American Diabetes Association: joint position statement. Diabetes Care. 2010;33(12):e147-67.

14. Medicine ACoS. ACSM's guidelines for exercise testing and prescription. 9th ed. Philadelphia: Lippincott Williams \& Wilkins; 2013.

15. Cadore EL, Pinto RS, Bottaro M, et al. Strength and endurance training prescription in healthy and frail elderly. Aging Dis. 2014;5(3):183-95.

16. Romero-Arenas S, Martinez-Pascual M, Alcaraz PE. Impact of resistance circuit training on neuromuscular, cardiorespiratory and body composition adaptations in the elderly. Aging Dis. 2013;4(5):256-63.

17. Busch AJ, Webber SC, Richards RS, et al. Resistance exercise training for fibromyalgia. Cochrane Database Syst Rev. 2013;(12):CD010884. doi:10.1002/14651858.CD010884.

18. Cheema BS, Chan D, Fahey P, et al. Effect of progressive resistance training on measures of skeletal muscle hypertrophy, muscular strength and health-related quality of life in patients with chronic kidney disease: a systematic review and metaanalysis. Sports Med. 2014;44(8):1125-38.

19. Cheema BS, Kilbreath SL, Fahey PP, et al. Safety and efficacy of progressive resistance training in breast cancer: a systematic review and meta-analysis. Breast Cancer Res Treat. 2014;148(2):249-68.

20. Heiestad H, Rustaden AM, Bo K, et al. Effect of regular resistance training on motivation, self-perceived health, and quality of life in previously inactive overweight women: a randomized, controlled trial. Biomed Res Int. 2016;2016:3815976.

21. Bassett DR Jr, Howley ET. Limiting factors for maximum oxygen uptake and determinants of endurance performance. Med Sci Sports Exerc. 2000;32(1):70-84.

22. Mooses M, Hackney AC. Anthropometrics and body composition in East African runners: potential impact on performance. Int J Sports Physiol Perform. 2016;15:1-27.

23. Schmidtbleicher D. Strength training (part 2): structural analysis of motor strength qualities and its application to training. Sci Period Res Tech Sport. 1985;4:1-10.

24. Gotshalk LA, Berger RA, Kraemer WJ. Cardiovascular responses to a high-volume continuous circuit resistance training protocol. J Strength Cond Res. 2004;18(4):760-4. 
25. Brown LE. Strength training United Kingdom, 2nd edn. Human Kinetics; 2007. p. 143-4.

26. Gettman LR, Pollock ML. Circuit weight training: a critical review of its physiological benefits. Phys Sportsmed. 1981;9(1):44-60

27. Alcaraz PE, Perez-Gomez J, Chavarrias M, et al. Similarity in adaptations to high-resistance circuit vs. traditional strength training in resistance-trained men. J Strength Cond Res. 2011;25(9):2519-27.

28. Paoli A, Pacelli F, Bargossi AM, et al. Effects of three distinct protocols of fitness training on body composition, strength and blood lactate. J Sports Med Phys Fitness. 2010;50(1):43-51.

29. Alcaraz PE, Sanchez-Lorente J, Blazevich AJ. Physical performance and cardiovascular responses to an acute bout of heavy resistance circuit training versus traditional strength training. J Strength Cond Res. 2008;22(3):667-71.

30. Hurley BF, Seals DR, Ehsani AA, et al. Effects of high-intensity strength training on cardiovascular function. Med Sci Sports Exerc. 1984;16(5):483-8.

31. Braun WA, Hawthorne WE, Markofski MM. Acute EPOC response in women to circuit training and treadmill exercise of matched oxygen consumption. Eur J Appl Physiol. 2005;94(5-6):500-4.

32. Gettman LR, Ward P, Hagan RD. A comparison of combined running and weight training with circuit weight training. Med Sci Sports Exerc. 1982;14(3):229-34.

33. Petersen SR, Haennel RG, Kappagoda CT, et al. The influence of high-velocity circuit resistance training on VO2max and cardiac output. Can J Sport Sci. 1989;14(3):158-63.

34. Allen TE, Byrd RJ, Smith DP. Hemodynamic consequences of circuit weight training. Res Q. 1976;47(3):229-306.

35. Dudley GA. Metabolic consequences of resistive-type exercise. Med Sci Sports Exerc. 1988;20(5 Suppl):S158-61.

36. Wilmore JH, Parr RB, Girandola RN, et al. Physiological alterations consequent to circuit weight training. Med Sci Sports. 1978;10(2):79-84.

37. Hickson RC. Interference of strength development by simultaneously training for strength and endurance. Eur J Appl Physiol. 1980;45(2-3):255-63.

38. Hickson RC, Rosenkoetter MA, Brown MM. Strength training effects on aerobic power and short-term endurance. Med Sci Sports Exerc. 1980;12(5):336-9.

39. Wilson JM, Marin PJ, Rhea MR, et al. Concurrent training: a meta-analysis examining interference of aerobic and resistance exercises. J Strength Cond Res. 2012;26(8):2293-307.

40. Kraemer WJ, Patton JF, Gordon SE, et al. Compatibility of highintensity strength and endurance training on hormonal and skeletal muscle adaptations. J Appl Physiol. 1995;78(3):976-89.

41. Harber MP, Fry AC, Rubin MR, et al. Skeletal muscle and hormonal adaptations to circuit weight training in untrained men. Scand J Med Sci Sports. 2004;14(3):176-85.

42. Liberati A, Altman DG, Tetzlaff J, et al. The PRISMA statement for reporting systematic reviews and meta-analyses of studies that evaluate healthcare interventions: explanation and elaboration. BMJ. 2009;339:b2700.

43. Maher CG, Sherrington C, Herbert RD, et al. Reliability of the PEDro scale for rating quality of randomized controlled trials. Phys Ther. 2003;83(8):713-21.

44. Deeks J, Higgins J, Altman D, et al. Cochrane handbook for systematic reviews of interventions version 5.1. 0 (updated March 2011). The Cochrane Collaboration; 2011.

45. DerSimonian R, Laird N. Meta-analysis in clinical trials. Control Clin Trials. 1986;7(3):177-88.

46. Higgins JP, Thompson SG, Deeks JJ, et al. Measuring inconsistency in meta-analyses. BMJ. 2003;327(7414):557-60.
47. Hopkins WG, Marshall SW, Batterham AM, et al. Progressive statistics for studies in sports medicine and exercise science. Med Sci Sports Exerc. 2009;41(1):3-13.

48. Bhogal SK, Teasell RW, Foley NC, et al. The PEDro scale provides a more comprehensive measure of methodological quality than the Jadad scale in stroke rehabilitation literature. J Clin Epidemiol. 2005;58(7):668-73.

49. de Morton NA. The PEDro scale is a valid measure of the methodological quality of clinical trials: a demographic study. Aust J Physiother. 2009;55(2):129-33.

50. Chtara M, Chamari K, Chaouachi M, et al. Effects of intra-session concurrent endurance and strength training sequence on aerobic performance and capacity. $\mathrm{Br} \mathrm{J}$ Sports Med. 2005;39(8):555-60.

51. Gettman LR, Ayres JJ, Pollock ML, et al. The effect of circuit weight training on strength, cardiorespiratory function, and body composition of adult men. Med Sci Sports. 1978;10(3):171-6.

52. Haennel R, Teo KK, Quinney A, et al. Effects of hydraulic circuit training on cardiovascular function. Med Sci Sports Exerc. 1989;21(5):605-12.

53. Kaikkonen H, Yrjama M, Siljander E, et al. The effect of heart rate controlled low resistance circuit weight training and endurance training on maximal aerobic power in sedentary adults. Scand J Med Sci Sports. 2000;10(4):211-5.

54. Messier SP, Dill ME. Alterations in strength and maximal oxygen-uptake consequent to nautilus circuit weight training. Res Q Exerc Sport. 1985;56(4):345-51.

55. Murray JW, Donlick RG, Haas JD, et al. Effects of a slow speed, high-intensity circuit weight training-program on strength, endurance, aerobic power and body-composition. Med Sci Sports Exerc. 1983;15(2):124-34.

56. Camargo MD, Stein R, Ribeiro JP, Schvartzman PR, et al. Circuit weight training and cardiac morphology: a trial with magnetic resonance imaging. Br J Sports Med. 2008;42(2):141-5.

57. Dorgo S, King GA, Rice CA. The effects of manual resistance training on improving muscular strength and endurance. J Strength Cond Res. 2009;23(1):293-303.

58. Esquivel AA, Welsch MA. High and low volume resistance training and vascular function. Int $\mathrm{J}$ Sports Med. 2007;28(3):217-21.

59. Mate-Munoz JL, Anton AJM, Jimenez PJ, et al. Effects of instability versus traditional resistance training on strength, power and velocity in untrained men. J Sports Sci Med. 2014;13(3):460-8.

60. Rahmani-Nia F, Arazi H, Rahimi R, et al. Effects of an eightweek circuit strength training program on the body images and anxiety in untrained college students. Med Dello Sport. 2011;64(3):297-308.

61. Buskirk E, Taylor HL. Maximal oxygen intake and its relation to body composition, with special reference to chronic physical activity and obesity. J Appl Physiol. 1957;11(1):72-8.

62. Kerksick CM, Mayhew JL, Grimstvedt ME, et al. Factors that contribute to and account for strength and work capacity in a large cohort of recreationally trained adult healthy men with high- and low-strength levels. J Strength Cond Res. 2014;28(5):1246-54.

63. Coffey VG, Hawley JA. The molecular bases of training adaptation. Sports Med. 2007;37(9):737-63.

64. Hawley JA, Hargreaves M, Joyner MJ, et al. Integrative biology of exercise. Cell. 2014;159(4):738-49.

65. Coffey VG, Hawley JA. Concurrent exercise training: do opposites distract? J Physiol. 2017;595(9):2883-96. 